\title{
Antagonistic fungal enterotoxins intersect at multiple levels with host innate immune defences
}

\author{
Xing Zhang $\oplus^{1}$, Benjamin W. Harding ${ }^{1}$, Dina Aggad $\oplus^{1}$, Damien Courtine $\odot^{1}$, Jia- \\ Xuan Chen $\odot^{2}$, Nathalie Pujol $\oplus^{1 *}$, Jonathan J. Ewbank $\oplus^{1 *}$ \\ 1 Aix Marseille Univ, CNRS, INSERM, CIML, Turing Centre for Living Systems, Marseille, France, 2 Institute \\ of Molecular Biology, Mainz, Germany \\ * pujol@ciml.univ-mrs.fr (NP); ewbank@ciml.univ-mrs.fr (JJE)
}

\section{f openaccess}

Citation: Zhang X, Harding BW, Aggad D, Courtine D, Chen J-X, Pujol N, et al. (2021) Antagonistic fungal enterotoxins intersect at multiple levels with host innate immune defences. PLoS Genet 17(6): e1009600. https://doi.org/10.1371/journal. pgen.1009600

Editor: Danielle A. Garsin, The University of Texas Health Science Center at Houston, UNITED STATES

Received: February 4, 2021

Accepted: May 12, 2021

Published: June 24, 2021

Peer Review History: PLOS recognizes the benefits of transparency in the peer review process; therefore, we enable the publication of all of the content of peer review and author responses alongside final, published articles. The editorial history of this article is available here: https://doi.org/10.1371/journal.pgen.1009600

Copyright: @ 2021 Zhang et al. This is an open access article distributed under the terms of the Creative Commons Attribution License, which permits unrestricted use, distribution, and reproduction in any medium, provided the original author and source are credited.

Data Availability Statement: All relevant data are within the manuscript and its Supporting Information files, with the exception of raw MS

\section{Abstract}

Animals and plants need to defend themselves from pathogen attack. Their defences drive innovation in virulence mechanisms, leading to never-ending cycles of co-evolution in both hosts and pathogens. A full understanding of host immunity therefore requires examination of pathogen virulence strategies. Here, we take advantage of the well-studied innate immune system of Caenorhabditis elegans to dissect the action of two virulence factors from its natural fungal pathogen Drechmeria coniospora. We show that these two enterotoxins have strikingly different effects when expressed individually in the nematode epidermis. One is able to interfere with diverse aspects of host cell biology, altering vesicle trafficking and preventing the key STAT-like transcription factor STA-2 from activating defensive antimicrobial peptide gene expression. The second increases STA-2 levels in the nucleus, modifies the nucleolus, and, potentially as a consequence of a host surveillance mechanism, causes increased defence gene expression. Our results highlight the remarkably complex and potentially antagonistic mechanisms that come into play in the interaction between coevolved hosts and pathogens.

\section{Author summary}

When a pathogenic fungus invades an animal, it can deploy a bewildering battery of molecular weapons: hundreds of proteins are injected directly into the host's cells to enable the fungus to grow and reproduce. We study a simple animal host, the nematode worm C. elegans and its natural enemy, the fungus Drechmeria coniospora, which has a large repertoire of uncharacterised potential "virulence factors". Here, we focused on just two of these fungal proteins, called enterotoxins. By producing each enterotoxin inside the epidermis of C. elegans, we were able to study their specific effect on the host, and in particular on the way in which they altered the host's immune defences. The two enterotoxins had strikingly different effects. One blocked the worms' ability to make protective antimicrobial peptides, while the other actually stimulated their production. By combining genetics, biochemistry and cell biology, we uncovered the basis of these antagonistic 
data for which files are available from the PRIDE repository with the dataset identifier PXD021929.

Funding: This work was supported by institutional grants from the Institut national de la santé et de la recherche médicale (INSERM), Centre national de la recherche scientifique (CNRS) and Aix-Marseille University to the CIML, and the Agence Nationale de la Recherche program grants ANR-16-CE150001-01, ANR-11-LABX-0054 (Labex INFORM) and ANR-11-IDEX-0001-02 (A*MIDEX) to JJE. Salary support came from the China Scholarship Council (XZ), ANR (BWH), the Labex INFORM (DA), the Turing Centre (ANR-16-CONV-0001; $A^{*}$ MIDEX; DC), the CNRS (NP) and INSERM (JJE). Worm sorting used the facilities of the French National Functional Genomics platform, supported by the GIS IBiSA and Labex INFORM. The imaging core facility of the CIML is supported by the French National Research Agency program (FranceBiolmaging; ANR-10-INBS-04-01). The funders had no role in study design, data collection and analysis, decision to publish, or preparation of the manuscript.

Competing interests: The authors have declared that no competing interests exist. actions. Each of the enterotoxins turned out to act by altering different aspects of the worms' biology, despite both interfering with host protein translation. Our findings provide a first insight into the molecular and cellular basis of enterotoxins in this particular host-pathogen battle.

\section{Introduction}

The co-evolution of host and pathogen species can be interpreted as a constant arms race, with rounds of reciprocal adaptations driving diversification and divergence on the molecular and macroscopic scales [1]. Thus, an examination of the virulence strategies of a host's natural pathogens can aid understanding the origin and function of innate immune mechanisms. Our studies focus on the interaction between the nematode Caenorhabditis elegans and its natural fungal pathogen Drechmeria coniospora. Having dissected in considerable detail C. elegans defences, we are now also addressing the biology of $D$. coniospora.

In silico analysis of the fungal genome revealed a large number of genes and gene families potentially involved in virulence [2]. Several approaches exist to address the role of such candidate virulence factors. For example, the corresponding gene could be knocked out in the $D$. coniospora genome, and the effect on virulence measured. Alternatively, the endogenous fungal gene could be engineered so that the resultant protein is tagged to allow its visualisation during infection and/or for the use of biochemistry to identify host protein targets. Both these strategies have been applied to D. coniospora [2]. For unknown reasons, however, the protocol we established for transformation of $D$. coniospora [3] no longer functions. This means that we are currently not able to generate mutants in specific $D$. coniospora genes. In order to study candidate virulence factors, we therefore adopted a strategy to express the corresponding genes directly in C. elegans. In a proof of principal, the Falkow laboratory had previously used such a method of heterologous expression, transforming worms with a gene encoding the catalytic subunit of pertussis toxin (PTX) from Bordetella pertussis, to find the exotoxin's conserved target [4]. More recently, we showed that expressing the Shigella virulence factor OspF (a MAP kinase inhibitor) in the epidermis of C. elegans blocked the induction of the antimicrobial (AMP) gene $n l p-29$ [5], one of the hallmarks of the innate immune response to $D$. coniospora infection [6]. Given the toxic nature of some virulence factors, we refined the method to allow tight control of transgene expression, specifically in the adult epidermis of $C$. elegans.

Heat-labile enterotoxins are common and potent virulence factors secreted by pathogenic bacteria. They include cholera and pertussis toxins. They have an $\alpha \beta_{5}$ structure, where $\alpha$ is the enzymatically active subunit and the $\beta$ subunits correspond to the receptor-binding moiety. After the $\beta$ subunits bind to their specific cell receptor, the toxin is transported into the host cell's cytosol by endocytosis. The $\alpha$ subunit is then cleaved into $\alpha 1$ and $\alpha 2$ fragments; $\alpha 1$ possesses ADP-ribosylation activity and will modify specific host protein targets [7]. In common with other fungi, $D$. coniospora has no genes encoding enterotoxin $\beta$ subunits, but does have an unusually large number of genes for enterotoxin $\alpha$ subunit proteins [8]. Most of these predicted proteins with a "heat-labile enterotoxin alpha chain" (PFAM: PF01375) domain also have a signal peptide [2] and are expected to be secreted directly into the host cytoplasm, where they could act as toxins, ADP-ribosylating specific targets. The others, lacking a signal peptide, may represent examples of intracellular toxins with a potential role in defence against nematode predation (see [9]). Here, we focused on representative secreted heat-labile enterotoxins and explored the consequences of their expression in C. elegans to understand better how $D$. coniospora is able to infect and harm its host. 


\section{Methods}

\section{C. elegans culture}

Strains used in this study, including SJL1, a kind gift from Adam Antebi, are listed in the S1 Table. All strains were maintained on nematode growth media (NGM) and fed E. coli strain OP50 [10]. Hygromycin-resistant transgenic worms were maintained on OP50-seeded NGM plates containing $0.2 \mathrm{mg} / \mathrm{ml}$ hygromycin B (Thermo Fisher). When large populations of agedmatched worms of such strains were required, young adult worms were bleached by standard alkaline hypochlorite treatment [10] and eggs allowed to hatch overnight in $50 \mathrm{mM} \mathrm{NaCl}$ with $0.2 \mathrm{mg} / \mathrm{ml}$ hygromycin. L1 larvae were washed three times in $50 \mathrm{mM} \mathrm{NaCl}$ to remove hygromycin and grown on standard OP50-seeded NGM plates. This proved an efficient way to select for transgenics, while having a minimal effect on worm physiology, as judged by assaying the expression of irg-1 (S1 Fig). Otherwise, to perform assays requiring moderate numbers of worms, including for confocal microscopy, young adult transgenic worms were transferred from hygromycin-supplemented onto standard NGM plates and their transgenic progeny selected manually on the basis of fluorescent marker gene expression, to avoid the potentially confounding effects of hygromycin (S1 Fig). In such cases, siblings without fluorescent marker gene expression were also picked to be used as controls.

\section{D. coniospora culture and infection}

D. coniospora (Swe3, derived from ATCC 96282 [11]) spores were amplified by infecting worms every one or two weeks in the lab. The method to grow spores is described in detail in [12]. Briefly, sterile $50 \mathrm{mM} \mathrm{NaCl}$ was added to plates containing infected worms. A sterile glass microspreader or an L-shaped Pasteur pipette was used to scrape spores gently from the agar surface until the solution became turbid. About $300 \mu \mathrm{l}$ of the freshly harvested spore solution was then added to a standard $10 \mathrm{~cm}$ OP50 plate with 1000-2000 synchronized L4 or young adult worms. The plate was dried in a laminar flow hood and incubated at $25^{\circ} \mathrm{C}$ for 1 day. Infected worms were harvested with $50 \mathrm{mM} \mathrm{NaCl}$ and transferred to an NGM plate supplemented with $100 \mu \mathrm{g} / \mathrm{ml}$ gentamicin and $100 \mu \mathrm{g} / \mathrm{ml}$ ampicillin. The plate was incubated at $25^{\circ} \mathrm{C}$ for 1 week. Spores were then harvested as above. For assays requiring infected worms, synchronized young adult worms obtained either following treatment with an alkaline hypochlorite solution or using an egg-laying window, were infected by adding $100 \mu \mathrm{l}$ of a fresh spore solution to a $4 \mathrm{~cm}$ OP50 plate (or $200 \mu \mathrm{l}$ spore solution to a $6 \mathrm{~cm}$ OP50 plate). Plates were dried briefly under a hood and then incubated at $25^{\circ} \mathrm{C}$.

\section{Plasmid construction}

D. coniospora (Swe3) cDNA was generated as previously described [2] and purified by QIAquick PCR Purification Kit (Qiagen, Cat No./ID: 28104). The fungal gene RJ55_04834/ g4535, without the 5' sequence corresponding to the predicted signal peptide, with an engineered ATG, and without the stop codon, was amplified from cDNA by PCR with Gibson assembly 5' and 3' primers that included NotI and ClaI sites, respectively (S2 Table). FLAG and tev sequences were synthesised by Integrated DNA Technologies (Leuven, Belgium). mKate2 was amplified from the plasmid pNP152 [13] with Gibson assembly primers. The vector backbone was amplified by PCR using the destination vector pSX103 that contains the promoter of col-19 [14], a generous gift from Andrew Chisholm, as the template. All the fragments were assembled using the Gibson assembly protocol [15] to give pZX12. The degron sequence was amplified from DNA extracted from the worm strain PX627 [16] and inserted into AscI-digested pZX12 using Gibson assembly to give pZX17. To make other plasmids, 
pZX17 was double digested by NotI and ClaI, and the RJ55_04834/g4535 gene fragment replaced with the appropriate alternative $D$. coniospora gene fragment, generated as described above. rps-0p::hygR was amplified from pSO5.3 [5] and inserted into the pSX103 vector (double digested with KpnI and NarI) using Gibson assembly to give the pZX13 plasmid.

\section{Transgenic strains}

Transgenic strains were obtained by microinjection of $20 \mathrm{ng} / \mu \mathrm{l}$ of each virulence factor construct, $20 \mathrm{ng} / \mu \mathrm{l} r p s-0 p::$ hygR and the coinjection marker unc-122p::GFP, a kind gift from Jean-Louis Bessereau, at a concentration of $40 \mathrm{ng} / \mu \mathrm{l}$ into JDW141 (eft-3p::TIR::P2A::: BFP-NLS-degron::tbb-2 3'UTR). This strain, for use with the auxin-inducible degron system, with an internal degradation control [17], was a generous gift of Jordan Ward. To generate the control hygR;frIs7 strain (IG1864), $60 \mathrm{ng} / \mu \mathrm{l} r p s-0 p::$ hygR and $60 \mathrm{ng} / \mu \mathrm{l} u n c-122 p:: \mathrm{GFP}$ were microinjected into IG274 (+;frIs7) worms that contain integrated nlp-29p::GFP and col-12p:: $d s R e d$ reporter transgenes [18]. All other strains were obtained by conventional crosses using various reporter strains (S1 Table).

\section{RNA extraction, reverse transcription and quantitative PCR}

Worms were harvested and washed three times with $50 \mathrm{mM} \mathrm{NaCl}$ and pelleted by centrifugation before Trizol extraction (Thermo Fisher Scientific) following the manufacturer's instructions. Reverse transcription was performed using High-Capacity cDNA Reverse Transcription Kit (Invitrogen). Quantitative real-time PCR was performed as described [19] by using SYBR Green PCR Master Mix (TaKaRa). Values were normalized to those of act- 1 and were analyzed by the cycling threshold method using the appropriate qRT-PCR primers (S2 Table). Control and experimental conditions were tested in the same run.

\section{Microscopy and image analysis}

Worms were picked into a drop of $0.25 \mathrm{mM}$ levamisole on a $2 \%$ agarose pad on a glass slide and observed using a Leica DMRBE microscope. Fluorescent images were taken with a Zeiss AxioCam HR digital colour camera and Axio-Vision Rel. 4.6 software (Carl Zeiss AG). Confocal microscopy used a Zeiss LSM 780. All image processing was done using Fiji software [20]. Comparative analyses were performed with image sets acquired on same day with the same settings on age-matched worms. The area and Feret's (caliper) diameter for lateral hyp7 nucleoli were measured with an automatic particle analysis method. Feret's diameter represents the longest distance between any two points along an object's boundary. For better information extraction, minimizing the background noise and to avoid over and under estimation, automatic thresholding was applied to images of each nucleolus, selected after pseudo-colouring based on pixel intensity and smoothing to discriminate better the area of interest. For any data that did not have a normal distribution (determined with a Shapiro-Wilk test), statistical significance was determined using a nonparametric Mann Whitney test (GraphPad Prism software).

\section{Analyses with the Biosort worm sorter}

Fluorescent protein expression of reporter strains was quantified with the COPAS (Complex Object Parametric Analyzer and Sorter) Biosort system (Union Biometrica; Holliston, MA) as described [18]. For each strain, a minimum of 150 synchronized young adult worms were analyzed for length (assessed as TOF, time of flight), optical density (assessed as extinction) and Green and/or Red fluorescence (GFP/Red). Raw data were filtered on the TOF for adult 
worms (typically $300 \leq \mathrm{TOF} \leq 1500$ ). Statistical significance was determined using a nonparametric analysis of variance with a Dunn's test (GraphPad Prism).

\section{RNA interference}

RNAi bacterial clones were obtained from the Ahringer or Vidal libraries [21,22] and checked by sequencing. RNAi bacteria were seeded on NGM plates with the appropriate antibiotics. Worms were transferred onto RNAi plates as L1 larvae and cultured at $20^{\circ} \mathrm{C}$ or $25^{\circ} \mathrm{C}$ as indicated.

\section{Lifespan}

L4 worms were manually transferred to small $(4 \mathrm{~cm})$ plates containing NGM agar seeded with E. coli OP50. Typically, for each strain, 5 plates of 10 worms were assayed. Worms were grown at $25^{\circ} \mathrm{C}$ and the surviving and dead worms were counted every day. Worms were transferred to new plates every day at the start of the experiment to eliminate the larvae of the next generation. Once worms had stopped producing viable eggs, they were kept on the same plates and the worms that no longer responded to light touch were picked out and scored as dead.

\section{Survival upon D. coniospora infection}

L4 or young adult worms were manually transferred to $4 \mathrm{~cm}$ plates containing NGM agar seeded with E. coli OP50. Fresh spores were harvested and spread on the plate. Normally, $1 \mathrm{x}$ $10^{8}$ spores were used for infecting about 100 worms on a $4 \mathrm{~cm}$ OP50 plate. After infection (either 8 hours or overnight), for each experimental condition, 4 wells of 25 worms were assayed in a 12-well plate containing NGM agar seeded with E. coli OP50. Images of each well were collected automatically every 24 minutes using a custom system that will be described elsewhere. The images were examined, and worms scored as dead when they no longer exhibited movement between successive images.

\section{Cuticle fragility test}

The cuticle fragility was tested by measuring the time to cuticle rupture in bleach as previously described [23].

\section{Cycloheximide (CHX) treatment}

CHX (40 mM in DMSO) was added to OP50-seeded NGM agar plates to a final concentration of $1.78 \mathrm{mM}(500 \mu \mathrm{g} / \mathrm{ml})$ and allowed to dry before use. Young adult worms that had been grown at $20^{\circ} \mathrm{C}$ on OP50 NGM plates were transferred to the plates with $\mathrm{CHX}$ for $6 \mathrm{~h}$. While exposure to this concentration of CHX for prolonged periods affects development and animal health [24], we found that adults tolerated this concentration well for short $(6 \mathrm{~h})$ periods.

\section{Preparation of worms for biochemistry}

Large quantities of worms were prepared using enriched NGM agar medium (NGM+; $3 \mathrm{~g}$ $\mathrm{NaCl}, 20 \mathrm{~g}$ peptone, $25 \mathrm{~g}$ agar, $1 \mathrm{ml}$ of $5 \mathrm{mg} / \mathrm{ml}$ cholesterol (in ethanol) in $975 \mathrm{ml}$ of $\mathrm{H}_{2} 0$ autoclaved, cooled then supplemented with $1 \mathrm{ml}$ of $1 \mathrm{M} \mathrm{CaCl}_{2}, 1 \mathrm{ml}$ of $1 \mathrm{M} \mathrm{MgSO}_{4}, 25 \mathrm{ml}$ of $1 \mathrm{M}$ Phosphate buffer, $1 \mathrm{~mL}$ of $100 \mathrm{mg} / \mathrm{mL}$ ampicillin), seeded with 10x concentrated HT115 sta-1 (RNAi) clone, and grown for $20-24 \mathrm{~h}$ at $37^{\circ} \mathrm{C}$ to obtain a thick bacterial lawn. During the amplification of strains, to select transgenic worms, seeded plates were supplemented with hygromycin at a final concentration of $0.2 \mathrm{mg} / \mathrm{ml}$. In the case of worms expressing DcEntA and $\mathrm{DcEntB}$, plates were additionally supplemented with auxin at a final concentration of 1 
$\mathrm{mM}$ to limit any potential reduction of fecundity associated with expression of the virulence factors.

Mixed stage worm populations were collected by using $50 \mathrm{mM} \mathrm{NaCl}, 0.05 \%$ Triton X-100 in $15 \mathrm{ml}$ tubes, then washed three times in $50 \mathrm{mM} \mathrm{NaCl}$ prior to standard alkaline hypochlorite treatment. The recovered eggs were then washed three times and allowed to hatch overnight in $3 \mathrm{ml}$ of $50 \mathrm{mM} \mathrm{NaCl}$ supplemented with $0.2 \mathrm{mg} / \mathrm{ml}$ hygromycin, with gentle agitation. The synchronised L1 worms were then added to NGM + plates, and grown at $25^{\circ} \mathrm{C}$ until they reached the young adult stage. The expression of the chimeric virulence protein was confirmed by the observation of the expected red fluorescence signal using a dissecting fluorescence microscope. Worm samples were then collected by using $50 \mathrm{mM} \mathrm{NaCl}, 0.05 \%$ Triton X-100 in $15 \mathrm{ml}$ tubes and then washed 3-4 times in $50 \mathrm{mM} \mathrm{NaCl}$, until the supernatant was cleared of bacteria, before freezing the worm pellets at $-80^{\circ} \mathrm{C}$.

\section{Immunoprecipitation assay}

Pellets of synchronised young adult worms $(0.8-1 \mathrm{ml})$ were thawed in the presence of an equal volume of $2 x$ lysis buffer (75 mM Hepes, pH 7.5; 1.5 mM EGTA; $1.5 \mathrm{mM} \mathrm{MgCl}_{2} ; 150 \mathrm{mM} \mathrm{KCl}$; $15 \%$ glycerol; $0.075 \%$ NP-40 to which Roche cOmplete Mini tablets containing a protease inhibitor cocktail were added just prior to use). Thawed worm pellets were then flash frozen in liquid nitrogen and then crushed using a pestle and mortar on dry ice prior to sonication in Diagenode $15 \mathrm{ml}$ tubes (C30010017) using a Diagenode BioRuptor Pico (10 cycles $15 \mathrm{~s}$ on; $45 \mathrm{~s}$ off) cooled to $4^{\circ} \mathrm{C}$. Lysates were then transferred to $2 \mathrm{ml}$ Eppendorf tubes, the concentration of NP-40 adjusted to $0.5 \%$ and centrifuged for $10 \mathrm{~min}$ at $8000 \mathrm{rpm}$ at $4^{\circ} \mathrm{C}$. The supernatant was then transferred in $900 \mu \mathrm{l}$ aliquots to fresh Eppendorf tubes and incubated with gentle headover-tail agitation for $2 \mathrm{~h}$ at $4^{\circ} \mathrm{C}$ with $30 \mu \mathrm{l}$ of anti-RFP or control beads (Chromotek rtma-2 and bmab-20, respectively) that had been washed in $1 \mathrm{x}$ lysis buffer. The beads were then washed once in Wash buffer I ( $25 \mathrm{mM}$ Tris- $\mathrm{HCl} \mathrm{pH} \mathrm{7.4,} 300 \mathrm{mM} \mathrm{NaCl}, 1 \mathrm{mM} \mathrm{MgCl} 2$ ) and twice in Wash buffer II ( $1 \mathrm{mM}$ Tris- $\left.\mathrm{HCl} \mathrm{pH} \mathrm{7.4,} 150 \mathrm{mM} \mathrm{NaCl}, 1 \mathrm{mM} \mathrm{MgCl}_{2}\right)$ and proteins then released from the beads through incubation in 1x Laemmli buffer at $95^{\circ} \mathrm{C}$ for 10 minutes.

\section{Protein in-gel digestion}

Proteins were separated briefly in a 4-12\% NuPAGE Bis-Tris gel, stained with Coomassie blue and cut into small gel cubes, followed by destaining in $50 \%$ ethanol $/ 25 \mathrm{mM}$ ammonium bicarbonate. The proteins were then reduced in $10 \mathrm{mM}$ DTT at $56^{\circ} \mathrm{C}$ and alkylated by $50 \mathrm{mM}$ iodoacetamide in the dark at room temperature. Afterwards, proteins were digested by trypsin $\left(1 \mu \mathrm{g}\right.$ per sample) overnight at $37^{\circ} \mathrm{C}$. Following peptide extraction through sequential incubation of gel cubes in $30 \%$ and $100 \%$ acetonitrile, the sample volume was reduced in a centrifugal evaporator (Eppendorf) to remove residual acetonitrile. The resultant peptide solution was purified by solid phase extraction in C18 StageTips [25].

\section{Liquid chromatography tandem mass spectrometry}

Peptides were separated in an in-house packed $50 \mathrm{~cm}$ analytical column (inner diameter: $75 \mu \mathrm{m}$; ReproSil-Pur 120 C18-AQ $1.9 \mu \mathrm{m}$ resin, Dr. Maisch GmbH) by online reversed phase chromatography through a 90 min gradient of $2.4-32 \%$ acetonitrile with $0.1 \%$ formic acid at a nanoflow rate of $250 \mathrm{nl} / \mathrm{min}$. The eluted peptides were sprayed directly by electrospray ionization into an Orbitrap Exploris 480 mass spectrometer (Thermo Scientific). Mass spectrometry measurement was conducted in data-dependent acquisition mode using a top 15 method with one full scan (resolution: 60,000, target value: $3 \times 10^{6}$, maximum injection time: $28 \mathrm{~ms}$ ) followed by 15 fragmentation scans via higher energy collision dissociation (HCD; normalised 
collision energy: $30 \%$, resolution: 15,000 , target value: $1 \times 10^{5}$, maximum injection time: 40 $\mathrm{ms}$, isolation window: $1.4 \mathrm{~m} / \mathrm{z}$ ). Precursor ions of unassigned, $+1,+7$ or higher charge state were rejected for fragmentation scans. Additionally, precursor ions already isolated for fragmentation were dynamically excluded for $25 \mathrm{~s}$.

\section{Mass spectrometry data analysis}

Raw data files were processed by MaxQuant software package (version 1.6.5.0) [26] using Andromeda search engine [27]. Spectral data were searched against a target-decoy database consisting of the forward and reverse sequences of WormPep release WS275 (28,466 entries), UniProt E. coli K-12 proteome release 2020_01 (4,403 entries), the corresponding transgenic fusion protein and a list of 246 common contaminants. Trypsin/P specificity was selected. Carbamidomethylation of cysteine was chosen as fixed modification. Oxidation of methionine and acetylation of the protein $\mathrm{N}$-terminus were set as variable modifications. A maximum of 2 missed cleavages were allowed. The minimum peptide length was set to be 7 amino acids. At least one unique peptide was required for each protein group. False discovery rate (FDR) was set to $1 \%$ for both peptide and protein identifications. A separate database search was performed in strain DcEntA to identify mono-ADP-ribosylation (MAR; $\mathrm{C}_{15} \mathrm{H}_{21} \mathrm{~N}_{5} \mathrm{O}_{13} \mathrm{P}_{2}, m / z$ 541.0611) sites on residues CDEKNRST as variable modifications and ribose, adenosine, AMP and ADP as diagnostic ions [28].

Protein quantification was performed using the LFQ label-free quantification algorithm [29]. Minimum LFQ ratio count was set to one. Both the unique and razor peptides were used for protein quantification. The "match between runs" option was used for transferring identifications between measurement runs allowing a maximal retention time window of $0.7 \mathrm{~min}$. All mass spectrometry raw data have been deposited to the PRIDE repository [30] with the dataset identifier PXD021929. DcEntA and DcEntB are referenced as pZX26 and pZX25, respectively. This dataset also includes pull-down data for three other structurally-unrelated virulence factors used to identify proteins that bound in a non-specific manner, as described below.

Statistical data analysis was performed using R statistical software. Only proteins quantified in at least two out of the three RFP pull-down replicates were included in the analysis. LFQ intensities were log-transformed. Imputation for missing values was performed for each pulldown replicate by random picking from a normal distribution that simulated low intensity values below the noise level. The LFQ abundance ratio was then calculated for each protein between the RFP pull-downs and the controls. Significance of the enrichment was measured by an independent-sample Student's $t$ test assuming equal variances. Specific interaction partners were then determined in a volcano plot where a combined threshold (hyperbolic curve) was set based on a modified $t$-statistic (SAM, significance analysis of microarrays) [31,32]. Proteins that passed the combined threshold in a second strain (PRIDE repository PXD021929) were considered as potential cross-reactive, non-specific binders and were filtered out from the volcano plot and summary spreadsheets.

\section{In silico analyses}

BLASTP searches were conducted at the NCBI on 09/11/20, using default parameters, but excluding D. coniospora entries. We used the command-line version of NoD (v1.3b) [33] available as a Conda package (https://anaconda.org/bioconda/clinod). In addition to the default parameters, we used "-clean_sequence" as some D. coniospora proteins in the dataset [2] contain Xs in their sequence. The default output of NoD was parsed using a Python script (enclosed as a Jupyter notebook; available on request). Gene class enrichment analyses used Wormbase release WS277. 


\section{Results}

\section{Enterotoxins have distinct expression patterns and impact physiology when expressed in the epidermis}

As part of our investigation of the virulence mechanisms of $D$. coniospora, we adopted the strategy of expressing individual candidate fungal proteins through transgenesis in C. elegans. We expressed them under the control of a promoter (col-19) that is principally active in the epidermis from the young adult stage onwards [34,35]. In anticipation of potential deleterious effects of residual virulence factor expression during development, we engineered the proteins as chimeric constructs, adding an auxin-inducible degron (AID) [36]. We also included tags for microscopy and biochemistry (mKate2 and Flag, respectively; Fig 1A). We used this approach to address the function of representative members of the large family of enterotoxin $\alpha$ (PF01375) domain proteins. Enterotoxins are well known as important mediators of bacterial virulence [7] and this protein family is expanded in D. coniospora [8]. Through manual curation, 23 enterotoxin $\alpha$ genes were predicted in the genome of the $D$. coniospora strain used here, distributed across all 3 chromosomes, including several clusters of paralogues, compared

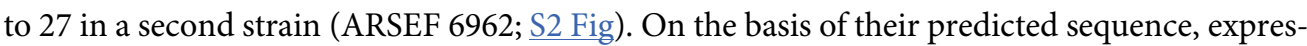
sion and position in a phylogenetic tree (S3 Fig), we selected three candidates (ODA75893.1/ RJ55_08534/g7949, ODA80052.1/RJ55_03010/g2819 and ODA76808.1/RJ55_07324/g6833) that we refer to here as DcEntA, DcEntB and DcEntC, respectively (Fig 1B). The 3 proteins have all the sequence features exhibited by other validated ADP-ribosylating enterotoxins and are presumed to be enzymatically active. When expressed as fusion proteins, each gave a distinct pattern of intracellular localisation in the main epidermal syncytium (hyp7). DcEntA was enriched in the perinuclear region as well as at the cell membrane, adjacent to seam cells (Fig 1C). DcEntB appeared to be restricted to the nucleolus, consistent with the presence of a predicted nucleolus-localisation signal (NoLS) in its primary sequence (Fig 1B and 1D). This was confirmed by its co-localisation with the known nucleolar marker FIB-1::GFP [37] (Fig 1D). DcEntC, on the other hand, gave a punctate, cytoplasmic pattern (Fig 1E). Any strategy of expressing chimeric proteins under the control of a heterologous promoter runs the risk of experimental artefacts. The very distinct patterns seen for the 3 chimeric DcEnt proteins, however, suggests that their localisation was not unduly influenced by the added non-fungal sequences that are common to all 3 proteins.

The different strains underwent larval development normally and we were able to maintain them under standard culture conditions. Except when amplifying large populations for biochemistry (see Methods, and below), we therefore conducted experiments on worms that had not been exposed to auxin, avoiding its possible confounding side effects [38]. After the $4^{\text {th }}$ larval stage (L4) to adult moult, coincident with the increasing activity of the col-19 promoter, fluorescence from the chimeric proteins started to be visible. As the worms aged and virulence factor expression increased (reflected by an increase in fluorescence), the strains expressing DcEntA and DcEntB manifested signs of sickness (Fig 2A and 2B and S3 Table) and the worms were short-lived. Worms expressing DcEntC, however, had more subtle phenotypes, an almost normal morphology and behaviour, and had a lifespan that was indistinguishable from control animals (Fig 2A and 2B and S3 Table). We therefore concentrated principally on the characterisation of DcEntA and DcEntB. Upon normal handling, adult DcEntA-expressing worms, but not DcEntB-expressing worms, appeared more prone to break apart. This was confirmed in the standard test of cuticle fragility, wherein the time to rupture for 2-day old adults expressing DcEntB was significantly shorter than for age-matched control worms (Fig 2C). On the other hand, both the DcEntA- and DcEntB-expressing worms were also significantly more susceptible to infection by D. coniospora than control worms (Fig 2D). Thus, 


\section{A}

col-19p GOI $(\triangle \mathrm{SigP}) \quad$ FLAG + TEV degron mKate2 unc-54 (3' UTR)

B

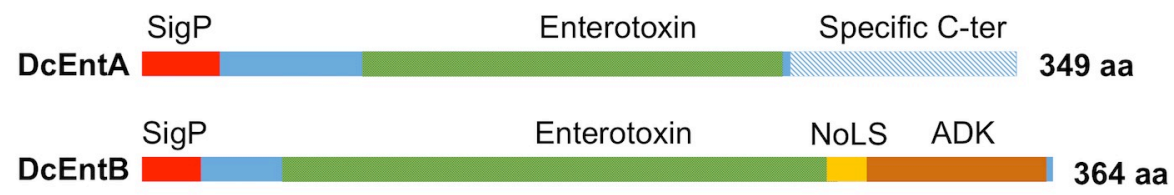

DcEntC

SigP

Enterotoxin

Rad50

C

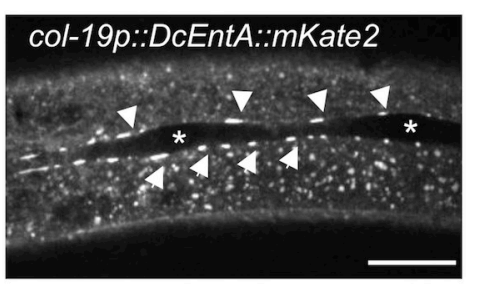

D

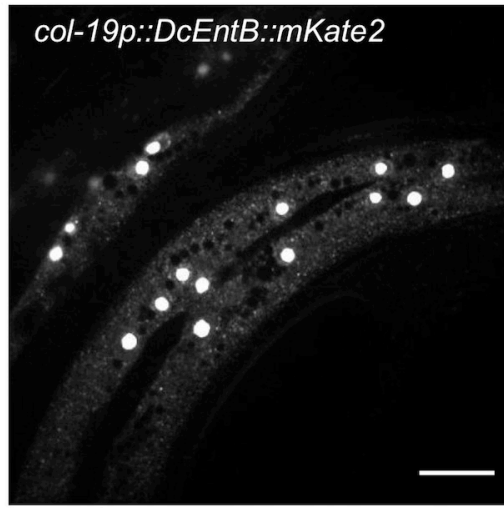

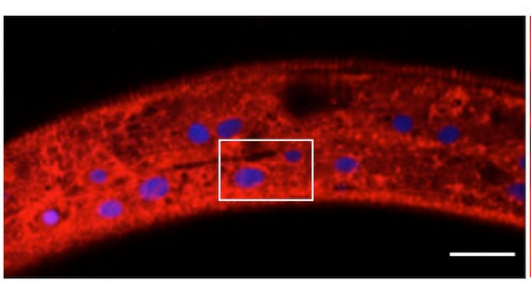

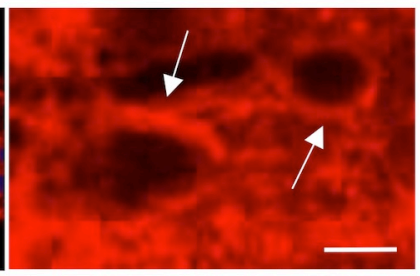

E
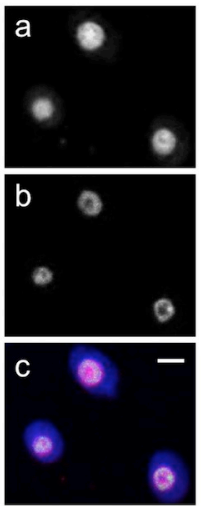

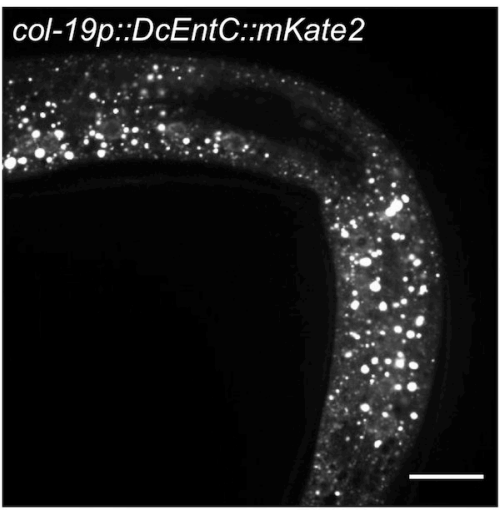

Fig 1. Three enterotoxins have different expression patterns in the epidermis. (A) Schematic overview of the plasmid insert used to express virulence factors. The candidate gene of interest (GOI), corresponding to a virulence factor without its signal peptide $(\Delta \operatorname{SigP})$ and stop codon was cloned between the col-19 promoter and unc-54 3' UTR, and expressed as a fusion protein with FLAG, tobacco etch virus (TEV) protease cleavage site, degron and mKate2. (B) Schematic overview of three selected enterotoxins from D. coniospora. The signal peptide (SigP) is represented in red, the heat-labile enterotoxin alpha chain domain (PFAM: PF01375) in green, a D. coniospora specific 90-residue C-terminal domain in DcEntA (hatched blue), the DcEntB nucleolar targeting sequence (NoLS) predicted by NoD [33] in yellow, the regions similar $\left(\mathrm{p}=9.44 \mathrm{e}^{-3}\right)$ to part of an adenylate kinase (ADK) domain (PRK13808), in brown, and DNA double-strand break repair ATPase Rad50 (PRK03918; 4.4e $\mathrm{e}^{-5}$ ) in dark blue for DcEntC. The remainder of the proteins' sequences is in light blue. Representative confocal fluorescence images of young adult worm expressing DcEntA::mKate2 (IG1926; C), DcEntB::mKate2 (IG1925; D), and DcEntC::mKate2 (IG1880; E). (C) Left panel: DcEntA (arrowheads) adjacent to seam cells (asterisks). Middle: DcEntA (red) accumulation around nuclei (blue) is highlighted with arrows in the right panel showing a magnified view of the boxed area. Scale bars, left and middle, $20 \mu \mathrm{m}$, right, $5 \mu \mathrm{m}$. (D) Left panel: young adult IG1925 worm expressing DcEntB::mKate2. Scale bar, $20 \mu \mathrm{m}$. Right: Image of young adult IG1984 worm expressing DcEntB::mKate2, FIB-1::GFP, and BFP-NLS (a: red channel; b: green channel; c: overlay red, green and blue channels). Scale bar, $5 \mu \mathrm{m}$. (E) DcEntC::mKate2 appears as a punctate cytoplasmic pattern. Scale bar, $20 \mu \mathrm{m}$.

https://doi.org/10.1371/journal.pgen.1009600.g001

controlled transgenic expression of certain individual fungal enterotoxins in the epidermis, albeit at an elevated level (S4 Fig), is sufficient to reduce C. elegans longevity and resistance to infection. 
A

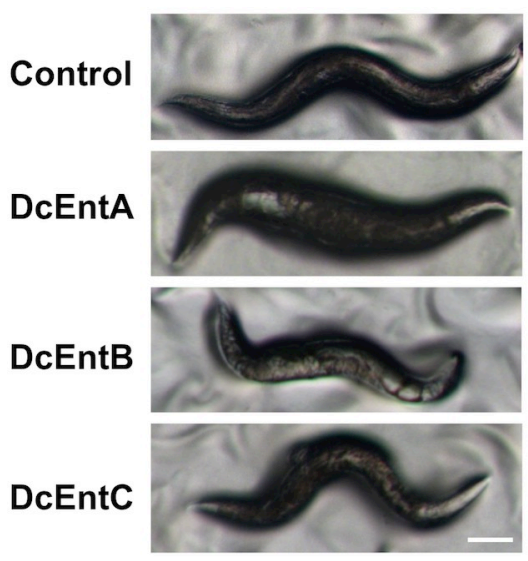

C

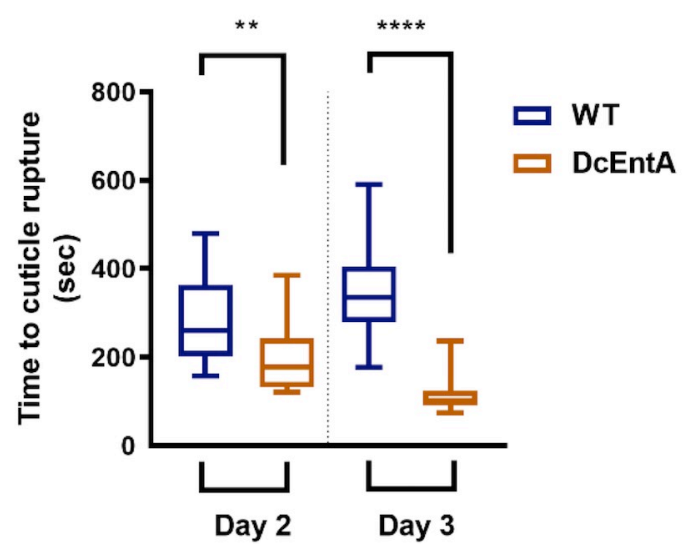

B

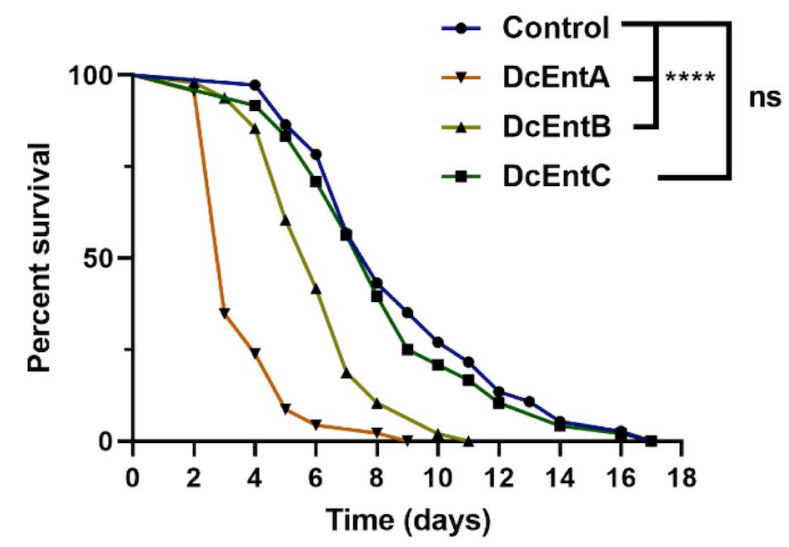

D

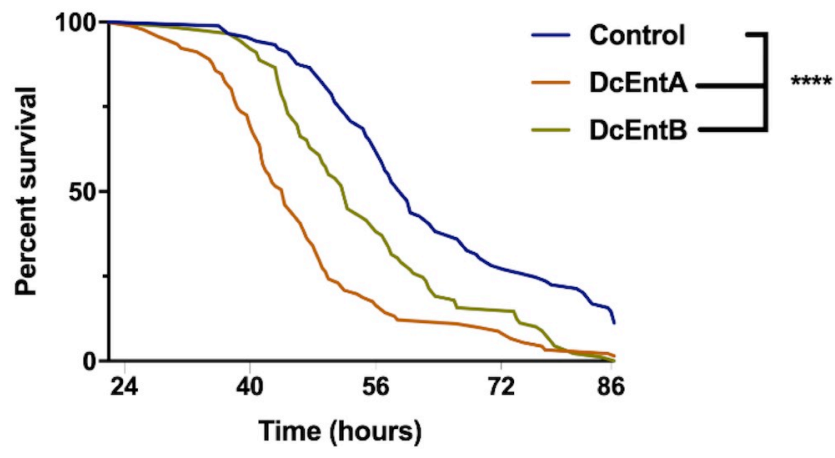

Fig 2. Expression of DcEntA or DcEntB makes worms sick and die precociously. (A) Representative images of control and enterotoxin-expressing worms on the third day of adulthood. From the top: control, DcEntA-, DcEntB- and DcEntC-expressing worms (JDW141, IG1926, IG1925 and IG1880, respectively); scale bar, $100 \mu \mathrm{m}$. (B) Lifespan counted from the L4 stage at $25^{\circ} \mathrm{C}$ of worms of these 4 strains. For each strain, $\mathrm{n}=50$. $^{* * * *}$ $\mathrm{p}<0.0001$, one-sided log rank test. (C) Expression of DcEntA increases cuticle fragility in 2- and 3-day old adult worms. Tukey boxplots ( $\mathrm{n}>20$, for each condition); unpaired t test, ${ }^{* *} \mathrm{p}<0.01 ;{ }^{* * * *} \mathrm{p}<0.0001$. (D) Survival of worms carrying frIs7 [nlp-29p::GFP and col-12p::dsRed] and a hygR transgene (control; IG1864) or also expressing DcEntA (IG1942) or DcEntB (IG1941) after infection as young adults with D. coniospora at $25^{\circ} \mathrm{C}$ $\left(\mathrm{n}=91,89\right.$ and 89 respectively). ${ }^{* * * *} \mathrm{p}<0.0001$, one-sided log rank test. Representative of 3 independent biological replicates.

https://doi.org/10.1371/journal.pgen.1009600.g002

\section{DcEntA blocks AMP gene expression after infection}

One of the key elements in the innate immune response of C. elegans to D. coniospora is the increased expression of a battery of AMP genes, including the well-studied $n l p-29[6,19,39]$. When we assayed the effect of DcEntA expression on the induction of an $n l p-29 p:: G F P$ reporter that is normally provoked by $D$. coniospora infection, we observed an almost complete block, that was not seen in worms expressing DcEntC. Notably, the level of the dsRed reporter, expressed in hyp7 under the constitutive col-12 promoter, was unchanged (Fig 3A and 3B). Using qRT-PCR, we confirmed the inhibitory effect of DcEntA on $n l p-29$ expression after infection. $n l p-29$ is one of a cluster of related AMP genes of the $n l p$ family that are all up-regulated upon D. coniospora infection [19]. The expression of a second family of AMP genes, the caenacins $(c n c)$, is also induced by the fungus $[6,40]$. By qRT-PCR, we observed that DcEntA blocked the expression of several AMP genes of both the $n l p$ and $c n c$ families (Fig 3C). Thus, DcEntA blocks AMP gene expression at the transcriptional level. 
A

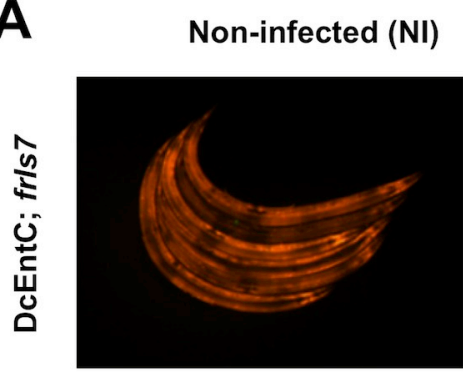

$$
\text { 产 }
$$

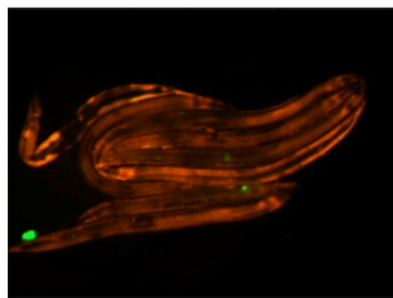

C

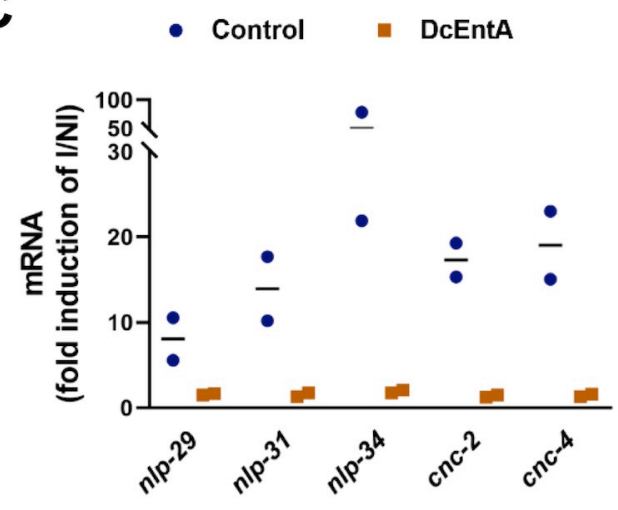

E

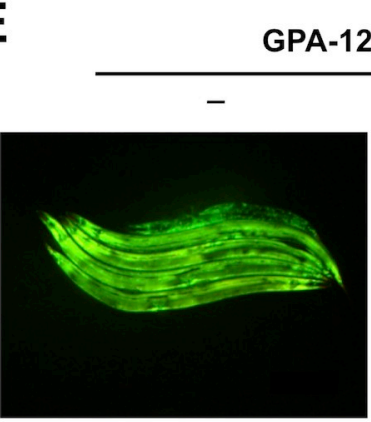

F

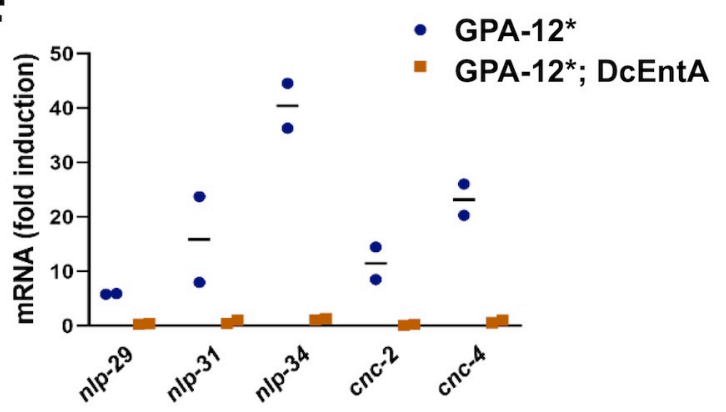

Infected (I)
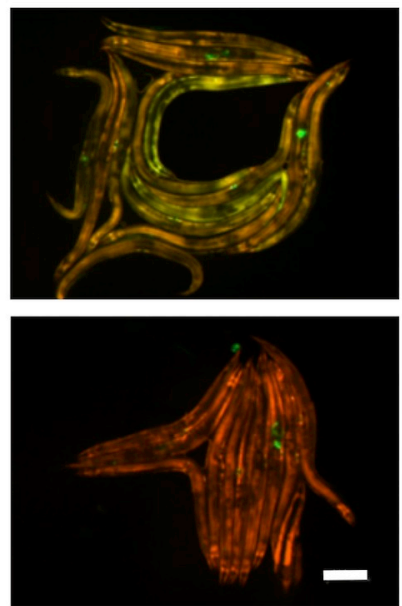

D
B
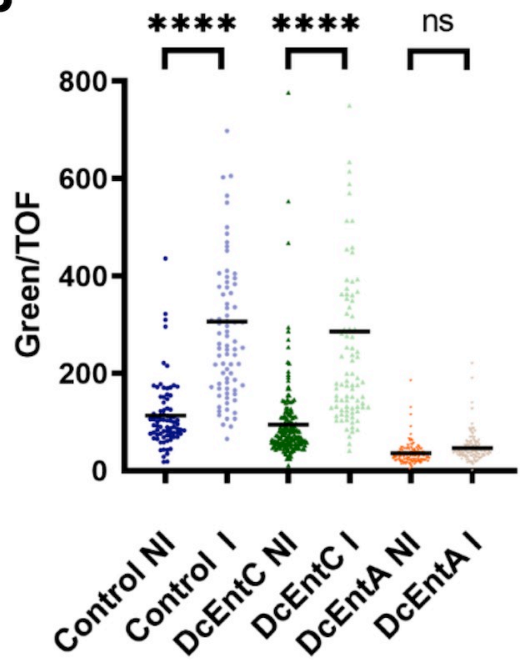

Infection

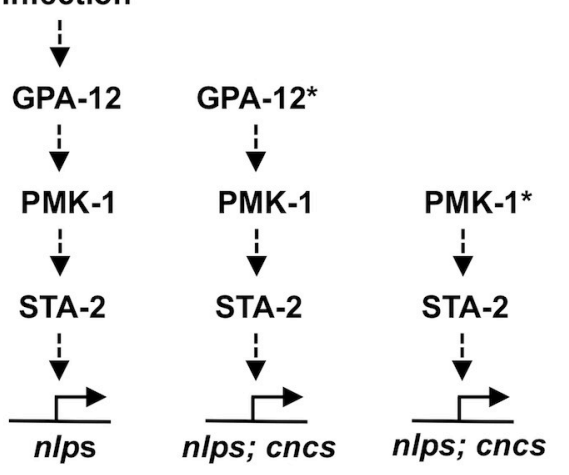

G

PMK-1*; frls 7
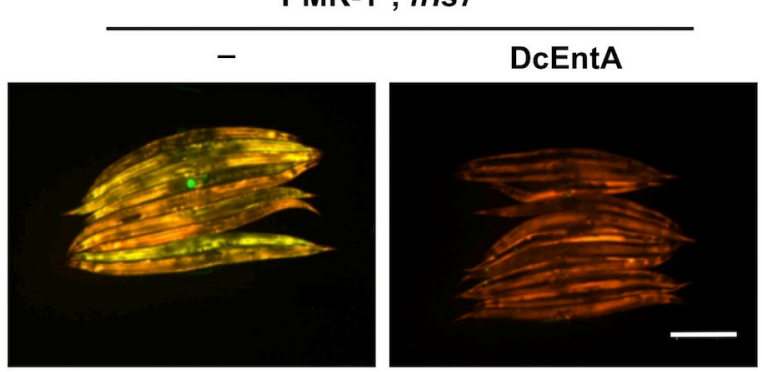

$\mathrm{H}$

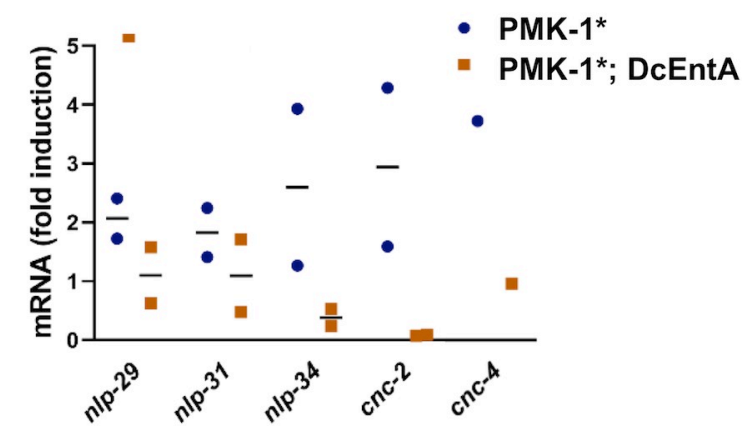

Fig 3. DcEntA blocks AMP gene expression after infection. (A) Representative images of DcEntC; frIs7 (IG1883; upper panels) and DcEntA; frIs7 (IG1942; lower panels) worms either not infected (left), or $20 \mathrm{~h}$ after infection with $D$. coniospora (right) as young adults. frIs $7 \mathrm{includes} n l p$ - 
29p::GFP and col-12p::dsRed transgenes; red and green florescence is visualized simultaneously. Scale bar, $200 \mu \mathrm{m}$. (B) Quantification of relative green fluorescence in worms carrying frIs7 and hygR transgenes (control; IG1864) or also expressing DcEntA (IG1942) or DcEntC (IG1883) either not infected (NI) or $20 \mathrm{~h}$ after infection (I) as young adults with D. coniospora at $25^{\circ} \mathrm{C}$. ${ }^{* * *} \mathrm{p}<0.0001$; ns, not significant, one way ANOVA test, $\mathrm{n}>80$. (C) Quantitative RT-PCR analysis of the expression of $n l p$ and $c n c$ genes in worms carrying frIs 7 and $h y g R$ transgenes (control; IG1864) or also expressing DcEntA (IG1942) after 18h of infection by D. coniospora. Results from 2 independent experiments are shown relative to the expression levels in age-matched uninfected worms. (D-H) DcEntA acts parallel to or downstream of $g p a-12$ and $p m k-1$ to block AMP gene expression. (D) D. coniospora infection activates a signal transduction pathway that, via the G $\alpha$ protein GPA-12, the p38 MAPK PMK1 and the STAT-transcription factor-like protein STA-2, positively regulates the expression of AMP genes of the $n l p$ family. The expression of $c n c$ family AMP genes is also induced, but via a distinct pmk-1-independent pathway [40] that converges on sta-2 [48]. In the absence of infection, expression of a constitutively active G $\alpha$ protein $\left(\mathrm{GPA}-12^{*}\right.$ ) or uncleavable p38 MAPK (PMK-1*) leads to higher expression of AMP genes of both the $n l p$ and $c n c$ families. (E, G) Representative images of young adult worms carrying $f r I s 7$, expressing GPA-12* (E) or PMK-1* (G) and expressing (right, IG1948 and IG1963) or not (left, IG1389 and BPW24) DcEntA. Red and green florescence is visualized simultaneously. Scale bar, $200 \mu \mathrm{m}$. (F, H) Quantitative RT-PCR analysis of the expression of $n l p$ and $c n c$ genes in worms expressing a constitutively active G $\alpha$ protein (GPA-12* (IG1389), F) or uncleavable p38 MAPK (PMK-1* (BPW24), H) and worms also expressing DcEntA (DcEntA;GPA-12* (IG1948), F; DcEntA;PMK-1* (IG1963), H). Results from 2 independent experiments are shown relative to the expression levels in age-matched IG1864 worms.

https://doi.org/10.1371/journal.pgen.1009600.g003

\section{DcEntA acts in parallel to, or downstream of, a canonical p38 MAPK pathway}

The main pathway regulating $n l p-29$ expression upon infection has been delineated [41-43]. It starts with activation of the G-protein coupled receptor DCAR-1 by the endogenous ligand HPLA [44] and signal transduction via the G $\alpha$ protein GPA-12 [45]. Expression of a constitutively active form of the latter (referred to as GPA-12*) recapitulates many of the transcriptional changes that accompany infection [5], including an increased expression of $n l p-29$ (Fig $3 D$ ), and also leads to a high level of expression of the $n l p-29 p:: G F P$ reporter, making this a useful tool for epistasis analysis [46].

When we crossed the DcEntA transgene into a strain expressing GPA-12*, we observed an abrogation of the high $n l p-29 p:: G F P$ reporter expression, and of the elevated expression of endogenous AMP genes as judged by qRT-PCR (Fig 3E and 3F). It should be noted that expression of GPA-12* down-regulates col-19 expression [5]. Thus, expression of the col-19p:: $D c E n t A$ transgene used here is decreased in a gpa-12* background (S5A and S5B Fig), and these worms showed a suppression of the increased susceptibility to D. coniospora infection normally associated with expression of DcEntA (S5C Fig). Notwithstanding this effect, together these results indicate that DcEntA acts in parallel to, or downstream of, gpa-12 to block defence gene expression.

The gpa-12 pathway feeds into a conserved p38 MAPK cascade that ends with pmk-1 [18]. The activity of $\mathrm{p} 38$ MAPK PMK-1 is normally limited by proteolysis by the caspase CED-3. Mutating the caspase cleavage site (changing Asp327 to Glu) in PMK-1 results in higher p38 MAPK activity and increased expression of nlp-29p::GFP [47]. When we crossed the DcEntA transgene into a strain carrying the pmk-1 (D327E) gain-of-function allele, we also observed a block of the elevated expression of the nlp-29p::GFP reporter and of endogenous AMP genes, although the effect was less dramatic than for the strain expressing GPA- $12^{*}$ since, as previously reported [47], constitutive levels of $n l p$ and $c n c$ gene expression were only moderately elevated in the pmk-1(D327E) background (Fig 3G and 3H). This indicates that DcEntA acts in parallel to, or downstream of, pmk-1 to block $n l p$ and $c n c$ AMP gene expression.

\section{DcEntA affects the key immune regulators SNF-12 and STA-2}

The p38 MAPK PMK-1 acts upstream of STA-2, a STAT-like protein. STA-2 is the common transcriptional regulator of $n l p$ and $c n c$ AMP genes. It interacts physically and functionally with the SLC6 protein SNF-12 [48]. When we crossed the DcEntA transgene into a strain expressing a SNF-12::GFP reporter protein, we observed a disruption of its normal vesicular 
pattern at the apical surface of the hyp7 epidermal syncytium (Fig 4A). In young adult transgenic worms with low DcEntA expression, the vesicular fluorescence was decreased (Fig 4B, upper panel, $\mathrm{n}>10$ ). A few hours later into adulthood, when DcEntA expression was higher, the SNF-12::GFP signal was largely diffuse within the cytoplasm, with some colocalisation of green and red fluorescence and accumulation at the boundary with the seam cells, as well as in a filamentous pattern at the apical surface of hyp7 (Fig 4B, middle and lower panels, $\mathrm{n}>10$ for each). Since SNF-12's correct intracellular localisation is essential for the induction of AMP gene expression [49], this disruption could be the cause of DcEntA's inhibitory effect.

STA-2 is found in both the cytoplasm and nuclei of the hyp7 epidermal syncytium of uninfected worms [48]. Upon D. coniospora infection, at early time points, it is technically challenging to correlate increasing AMP expression with the translocation of STA-2 into epidermal nuclei in individual worms, due in part to the inhomogeneous adhesion of spores to the worms' surface. Later, when infection is more homogeneous, increased AMP gene expression is accompanied by a significantly higher level of nuclear STA-2 (S6 Fig). Expression of DcEntA alone, in the absence of infection, significantly reduced the amount of a STA-2::GFP reporter protein within the nucleus (Fig 4C-4E). Thus, since STA-2 has DNA-binding ability (J. Polanowska, personal communication) and is expected to be a direct transcriptional regulator, DcEntA could abrogate $n l p$ and $c n c$ AMP gene expression by preventing the accumulation of STA-2 in the nucleus upon infection, potentially indirectly, through an effect on membrane trafficking and the activity of SNF-12.

\section{DcEntA increases the expression of ifas-1}

Both $n l p$ and $c n c$ AMP genes are positively regulated by the STAT-like transcription factor STA-2 [48]. The gene ifas-1 ("inducible fascin domain-containing"; F40H7.12), on the other hand, is induced upon D. coniospora infection [50] but this does not require sta-2 [51]. When we knocked down sta-2 expression by RNAi in worms expressing GPA-12*, we observed the expected decrease in the expression of the AMP gene $n l p-34$, but a significant increase in the expression of ifas-1 (Fig 5A). Similarly, upon infection, knocking down sta-2 specifically in epidermis (in strain IG1502 [52]) decreased expression of the AMP genes $n l p-34$ and $c n c-2$, but provoked a significant increase in the expression of ifas-1 (Fig 5B). In vertebrates, as well as acting as positive regulators of gene expression, STAT proteins can directly repress the accessibility and transcription of specific loci [53]. Indeed, the only other STAT protein in $C$. elegans, STA-1, is known to be a repressor of virus infection response genes [54]. Our results suggest that in addition to acting as a positive regulator of AMP gene expression, STA-2 acts in a cell-autonomous manner to repress ifas- 1 expression. Consistent with this model, the expression of ifas-1 was markedly increased by DcEntA and this effect was abrogated when STA-2 was activated in the GPA-12* background (Figs 5C and S5D). Thus, we hypothesise that DcEntA exerts opposite effects on the expression of ifas- 1 and of the $n l p$ and $c n c$ AMP genes by decreasing the level of STA-2 in the nucleus.

\section{D. coniospora infection and DcEntA inhibit translation}

ifas-1 shares some of the characteristics of "Intracellular Pathogen Response" genes [55], including regulation by pals-22 and pals-25 [56], and the fact that like irg-1 and irg-2 [57], its expression is strongly induced by the translational elongation inhibitor cycloheximide (CHX; Fig 5E and 5F). Thus, upon D. coniospora infection, or heterologous expression of DcEntA, the level of ifas-1 transcription is potentially increased as a consequence of translation inhibition. 
A SNF-12::GFP

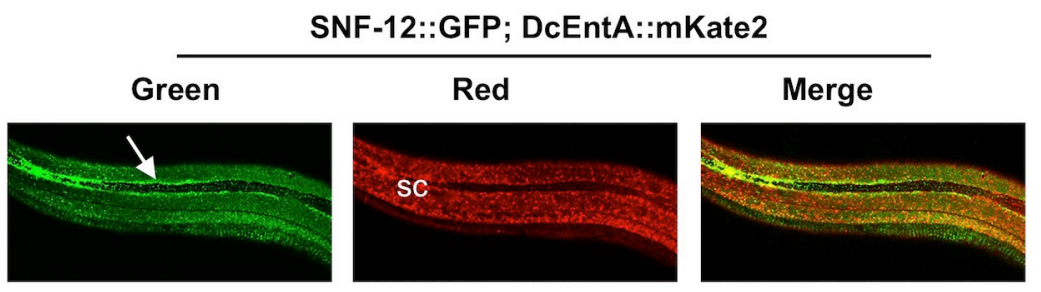

B
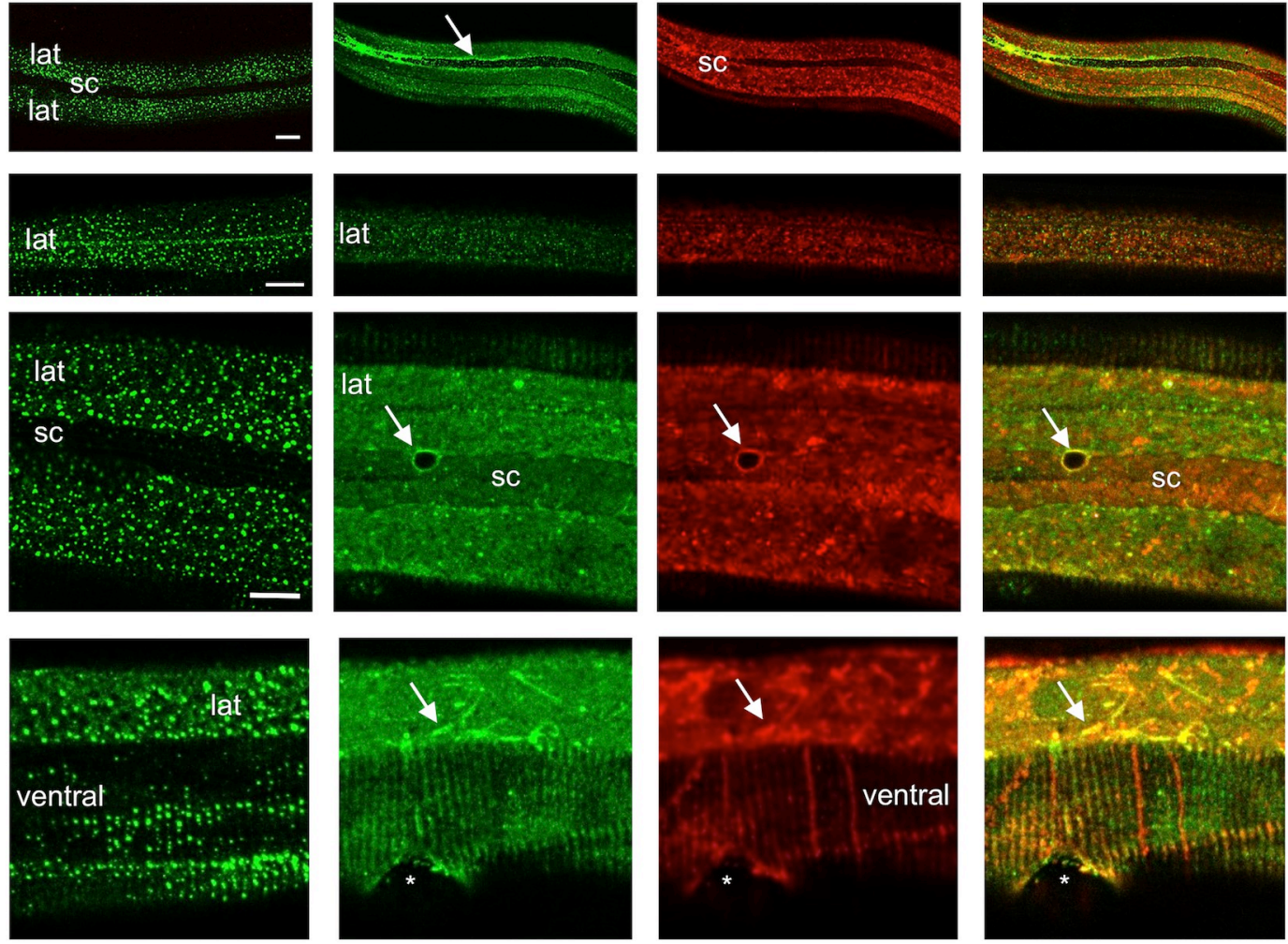

C

STA-2::GFP

$\mathbf{D}$

STA-2::GFP; DcEntA::mKate2
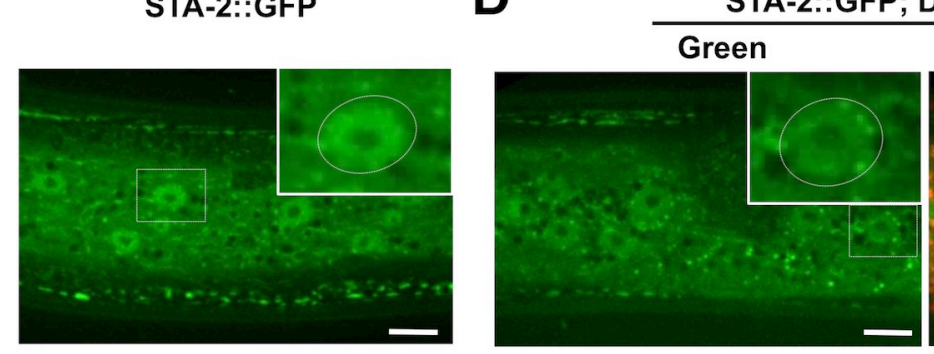

Merge

$\mathbf{E}$

- Control $] * * * *$

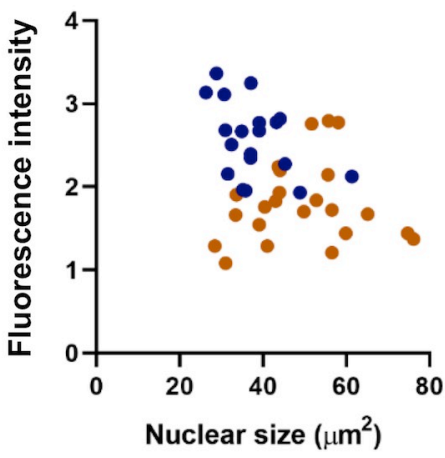

Fig 4. DcEntA alters the localisation of key immune regulatory proteins. (A, B) DcEntA disrupts the vesicular pattern of SNF-12 in the epidermis. Confocal images of adult worms expressing SNF-12::GFP together with DcEntA::mKate2 (IG1998, 
right-hand panels, in order, green, red, and green and red channels together) and their siblings without the DcEntA transgene (left panel, green channel only). (A) The normal vesicular expression of SNF-12 in the lateral epidermis (lat) is disrupted in young adult worms expressing DcEntA and an accumulation of green fluorescence (arrow) is observed at the junction with the seam cell (sc). (B) When DcEntA expression is low in very young adults (upper panels), some of the SNF-12 vesicular pattern is retained. In older worms, when DcEntA is more highly expressed (lower panels), the SNF-12 pattern is diffuse in the lateral epidermis (lat) and underneath the muscle (ventral) and some aggregates can be observed to colocalise with DcEntA (arrow). Scale bar $10 \mu \mathrm{m},\left({ }^{*}\right.$, vulva), $\mathrm{n}>10$. (C-E) DcEntA decreases STA-2 nuclear accumulation. Confocal images of young adult worms expressing STA-2:: GFP with DcEntA::mKate2 (IG1971, D; left panel green channel only, right panel green and red channels shown together) and their siblings without the DcEntA transgene (C). STA-2::GFP levels are reduced in the epidermal nucleus (white box, enlarged insert; highlighted by white oval) in the presence of DcEntA. Scale bar, $20 \mu \mathrm{m}$. (E) Intensity of green fluorescence in the nuclei of DcEntA;STA-2::GFP worms (DcEntA, IG1971, brown) and their siblings without the DcEntA transgene (Control, blue), plotted against nuclear size, measured using Fiji. Each dot represents a nucleus; $n>20$. The difference between the 2 populations is significantly different $\left({ }^{* * * *} \mathrm{p}<0.0001\right.$; unpaired t-test).

https://doi.org/10.1371/journal.pgen.1009600.g004

The capacity to detect perturbation of normal protein synthesis is an important part of the response of C. elegans to Pseudomonas aeruginosa infection [57,58]. In this case, it involves the bZIP transcription factor ZIP-2 [59] that, on the basis of publicly available ModERN ChiP-seq data [60], directly regulates irg-1 and irg-2. On the other hand, neither irg-1 nor $\mathrm{irg}-2$ is induced after 12 or 24 hours of infection by D. coniospora [50], and in line with the ModERN ChiP-seq data, zip-2 has not been reported to regulate ifas-1 expression [59]. As described above, the expression of ifas-1, as well as of irg-1, was markedly increased by DcEntA (Fig 5C and 5D), consistent with DcEntA interfering with translation.

To extend these observations, we examined the effect of infection on an ATF4/ATF-4 reporter gene. This contains two upstream open reading frames (uORF) before the GFP coding sequence [61]. Under normal conditions, the uORFs are translated, to the detriment of GFP expression. When translation rates are reduced, ribosomal scanning can bypass the uORFs, and translation re-initiation occur at the downstream initiation site, leading to translation of GFP [62]. Infection of adult worms carrying the atf-4p(uORF)::GFP reporter by $D$. coniospora was associated with a marked increase in GFP expression (S7 Fig). A strain carrying the atf-4p(uORF)::GFP reporter and also expressing DcEntA exhibited high GFP in the adult epidermis in the absence of infection (Fig $5 \mathrm{G}$ and $5 \mathrm{H}$ ). Together, these results are consistent with D. coniospora infection, and expression of DcEntA alone, causing a reduction in translation in the epidermis, a hitherto uncharacterised effect.

Expression of ATF-4 can be increased in response to endoplasmic reticulum (ER) stress through PERK1/PEK-1 phosphorylation of the initiation factor eIF2 $\alpha$, which reduces global translation rates [63]. PERK1/PEK-1 activation is also a hallmark of the ER unfolded protein response $\left(\mathrm{UPR}^{\mathrm{ER}}\right)$ [64]. Infection of adult worms does not induce the $\mathrm{UPR}^{\mathrm{ER}}$, or the expression of UPR ${ }^{\mathrm{ER}}$ genes such as $h s p-4$ [65]. Expression of DcEntA in the adult epidermis did not increase $h s p-4$ expression either. Further, the expression of $h s p-6$ and $h s p-60$ that are markers of the mitochondrial UPR, as well as $g s t-4$ (oxidative stress) and $g p d h-1$ (osmotic stress) [6670], showed no increase of expression in worms expressing DcEntA (S8 Fig). Together these results indicate that DcEntA exerts a specific inhibitory effect on the expression of $n l p$ and $c n c$ AMP genes that are positively regulated by $s n f-12$ and $s t a-2$. This is not the consequence of a generalized suppression of gene expression, since DcEntA increases expression of the infection-regulated gene, ifas-1, potentially as it interferes with translation, and in part as a consequence of reducing a suppressive effect of sta-2.

\section{DcEntA likely has ADP-ribosylation activity}

As a first step to understand the basis of these pleiotropic effects, we took an unbiased biochemical approach to identify proteins that interacted with DcEntA in vivo. From a synchronized population of adult worms expressing the DcEntA fusion protein, we pulled down 
A

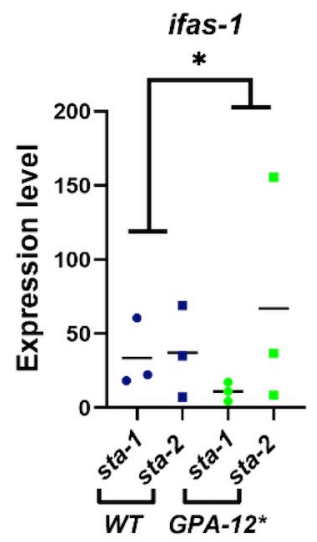

C

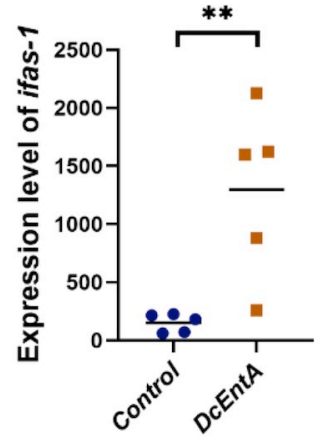

G

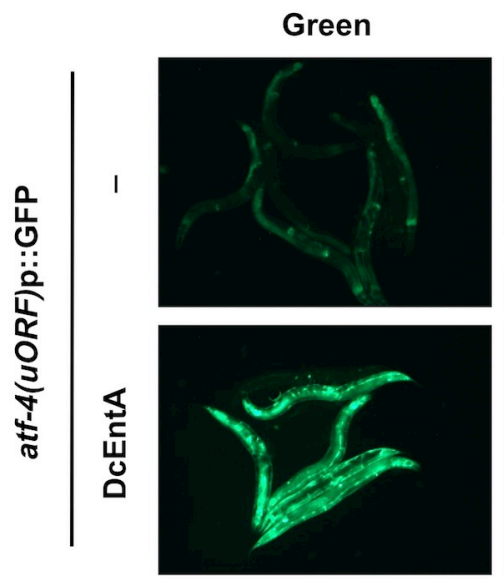

B

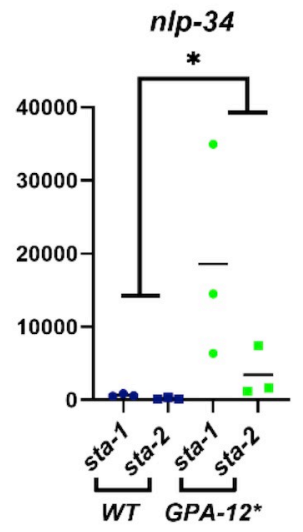

- NI - Infec
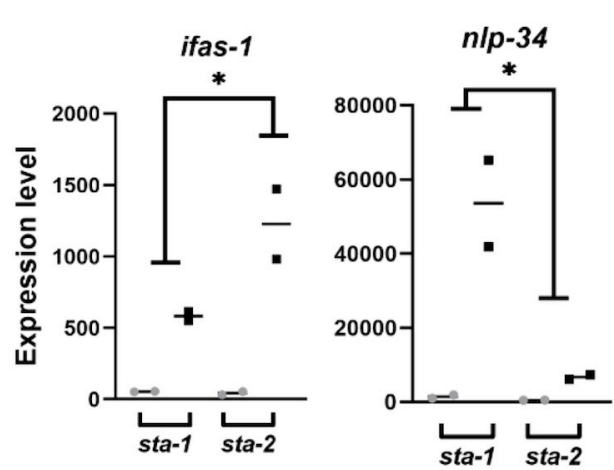

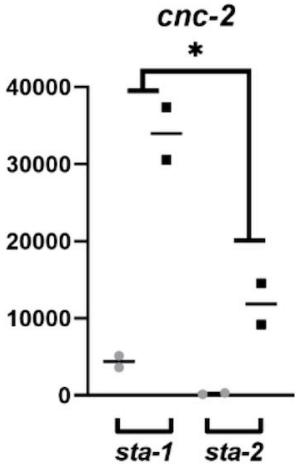

D

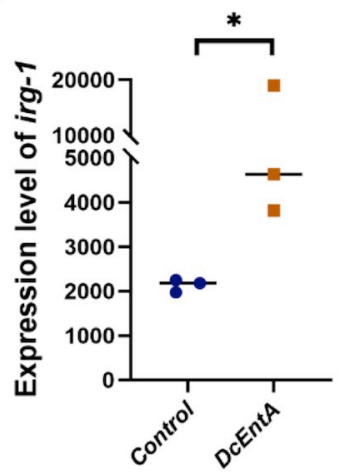

E

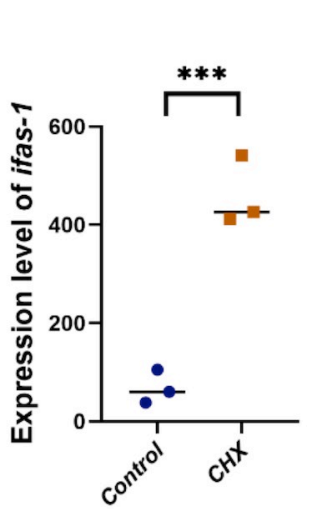

$\mathbf{F}$

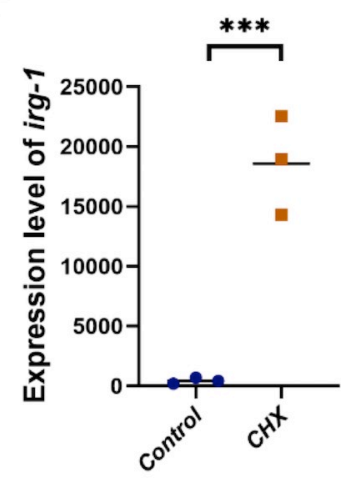

H
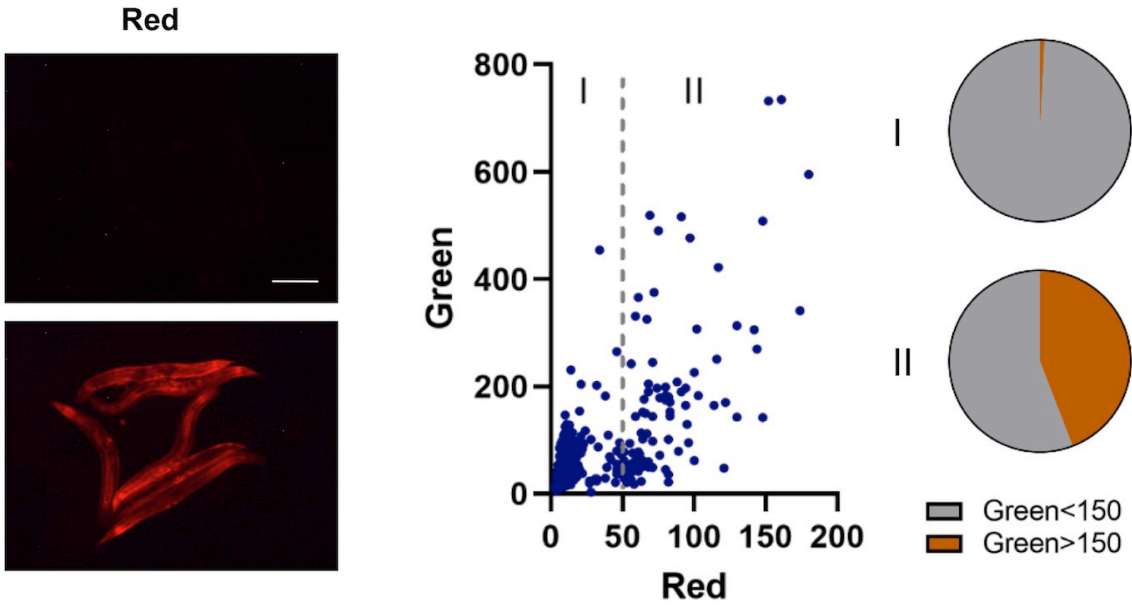

Fig 5. DcEntA induces expression of ifas-1, a target of negative regulation by sta-2, and inhibits translation. (A) Quantitative RT-PCR analysis of the expression of ifas- 1 and $n l p-34$ in control (hygR:frIs7 IG1864) worms and worms expressing GPA-12* (IG1389) following RNAi against sta-1 or sta-2. Data from three independent experiments are shown. (B) Quantitative RT-PCR analysis of the expression of ifas-1, nlp-34 and cnc-2 following RNAi against sta-1 or sta-2 in worms infected for $18 \mathrm{~h}$ (Infec) and non-infected (NI) controls in the epidermis-specific RNAi strain IG1502. Data from two independent experiments are shown. (C, D) Quantitative RT-PCR analysis of the expression of ifas-1 (C) and irg-1 (D) genes in young adult worms carrying hygR and frIs7 with (IG1942) or without DcEntA (control; IG1864). (E, F) Quantitative RT-PCR analysis of the expression of ifas-1 (E) and $\operatorname{irg}-1$ (F) in control worms (carrying frIs7 [nlp-29p::GFP; col-12p::dsRed]; IG274) or following exposure to cyclohexamide (CHX) for $6 \mathrm{~h}$. (G) Representative fluorescence images of adult worms carrying an atf- $4 p(u O R F):$ GFP (Green) reporter also expressing DcEntA::mKate2 (Red, IG2044; bottom panels) and their siblings without the DcEntA transgene (upper panels). Scale bar, $200 \mu \mathrm{m}$. (H) Relative green fluorescence plotted against red 
fluorescence in the mixed progeny of IG2044 worms. Each dot represents a single worm (left panel). As the DcEntA transgene is not integrated, the population contains worms expressing or not DcEntA. They can be distinguished on the basis of the red fluorescence associated with DcEntA. Right panel: the proportion of the worms with a high ( $>150$ a.u.) green fluorescence among those with a low ( $<50$, population $\mathrm{I}, \mathrm{n}=892)$ or high $(>50$, population II, $\mathrm{n}=102$ ) level of red fluorescence. In population I, that corresponds to worms that do not express DcEntA, only $0.78 \%$ have Green $>150$, while in population II, $44.12 \%$ do. (A-F) paired one-sided $\mathrm{t}$ test, ${ }^{*} \mathrm{p}<0.05 ;{ }^{* *} \mathrm{p}<0.01 ;{ }^{* * *} \mathrm{p}<0.001$. (A) and (B) the fold-change in expression level between the 2 indicated conditions is significantly different.

https://doi.org/10.1371/journal.pgen.1009600.g005

DcEntA::FLAG::Degron::mKate2 by immunoprecipitation from whole worm extracts and subjected the purified proteins to mass spectrometry analysis. Samples from four other strains of transgenic worms, each expressing a different candidate virulence factor, were processed in parallel (see below; Harding et al., in preparation). These were used as control samples, allowing proteins that specifically interacted with DcEntA to be identified. As expected, DcEntA itself featured among the most abundant proteins identified (Fig 6A and S4 Table). Detailed examination of its spectrum supported the presence of at least one site with an ADP-ribosylation modification, at an asparagine in the non-conserved C-terminus of the protein (S9 Fig). This suggests that in common with some bacterial exotoxins [7], DcEntA is able to auto-ADPribosylate.

Cholera toxin from Vibrio cholera requires a host protein, ADP ribosylation factor (ARF), in order to ADP-ribosylate its targets [71,72]. Notably, the 2 nematode orthologues of human ARF1 and ARF3, ARF-1.2 and ARF-1.1, respectively, were found among the 245 candidates interactors of DcEntA, consistent with a conserved mode of action for this fungal heat-labile enterotoxin. Attempts to confirm the functional relevance of this interaction were hampered by the essential role of ARF proteins; arf-1.2(RNAi) alone, or in combination with arf-1.1 (RNAi) rendered worms sick, and we did not pursue the question further.

\section{DcEntA potentially affects diverse aspects of host cell physiology}

To get an overall view of the proteins that were identified by mass spectrometry as candidate interactors of DcEntA, we used the gene set enrichment analysis tools available within Wormbase [73]. Among the enriched phenotype classes, given the disruptive effect of DcEntA on the vesicular pattern of SNF-12, "vesicle organization variant" (WBPhenotype:0001671; $\mathrm{p}=5.4 \times 10^{-3}$ ) stood out. With regards gene ontology, the most highly over-represented term was the "Cellular Component" class "ribonucleoprotein granule" (GO:0035770; $\left.\mathrm{p}=5.6 \times 10^{-6}\right)$. This class is for components of a "non-membranous macromolecular complex containing proteins and translationally silenced mRNAs". This is consistent with the observed increase in irg1 expression, a marker of translation inhibition $[57,58]$, provoked by DcEntA, and the enrichment for "peptide biosynthetic process" (GO:0043043; $\mathrm{p}=1.2 \times 10^{-4}$ ) and several other translation-related classes (S5 Table). DcEntA also disrupts membrane trafficking and we found an enrichment in the class "cellular macromolecule localization" (GO:0070727; $\mathrm{p}=1 \times 10^{-4}$ ). Indeed, several components of $C$. elegans intracellular vesicle transport machinery were identified, including 16 that have been reported to interact physically with VPS-45, orthologue of human VPS45 (vacuolar protein sorting 45 homolog), required for RAB-5-dependent endocytic transport [74], and 11 interactors of LET-413 [75], the nematode Erbin protein that acts as a RAB-5 effector during endocytic recycling and that physically interacts with RAB-5 [76]. Consistent with these observations, DcEntA was found in RAB-5-associated vesicles (Fig 6B). Notably, similar to the observed effect of DcEntA on the pattern of SNF-12::GFP (Fig 4B), the normal pattern of RAB-5 expression was disrupted in worms expressing high levels of DcEntA, with fewer RAB-5-positive vesicles and a more diffuse pattern of fluorescence (Fig 6C, $n>10$ worms). 
A

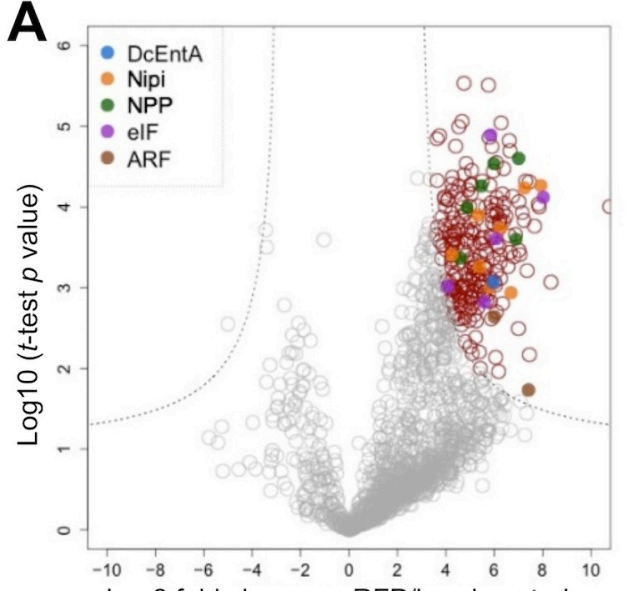

C
B
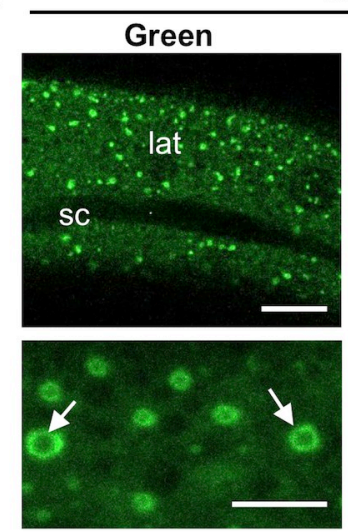

RAB-5::GFP; DcEntA::mKate2
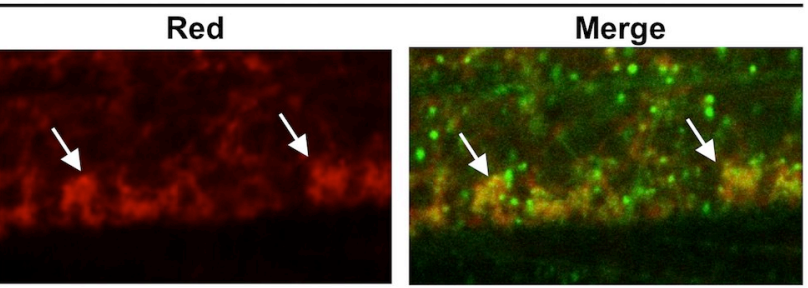

D
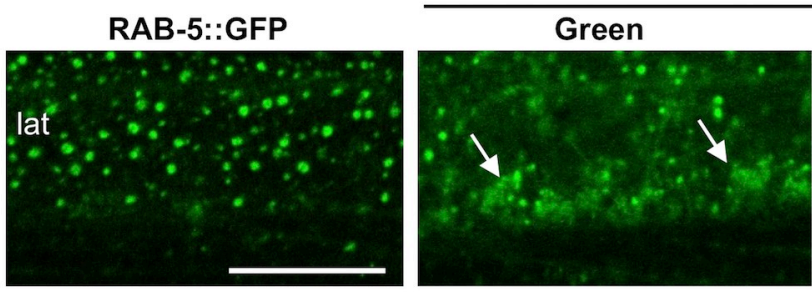

ERM-1::mNG; DcEntA::mKate2
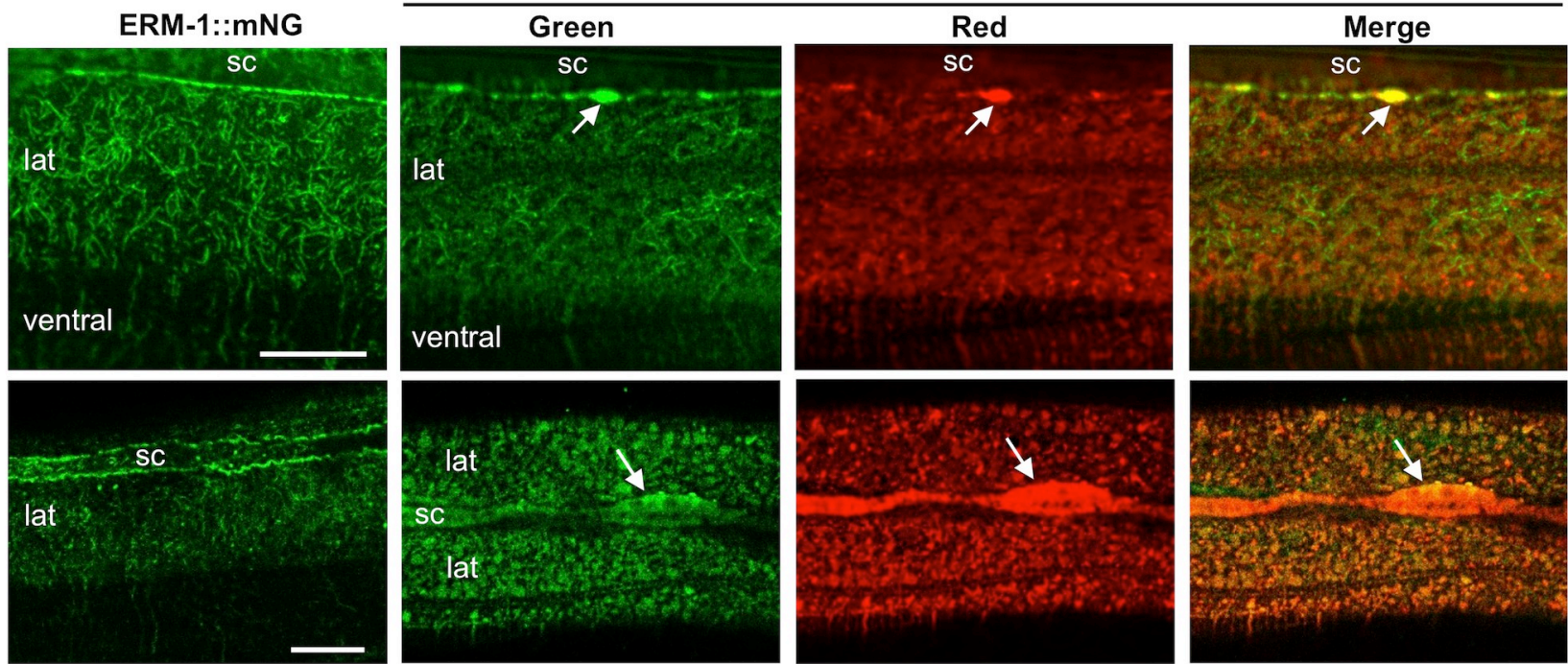

$\mathbf{E}$
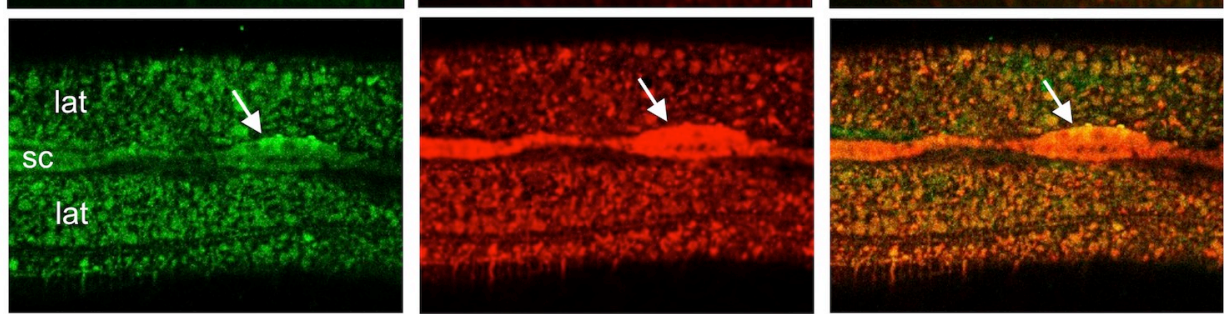

Lifeact::GFP; DcEntA::mKate2
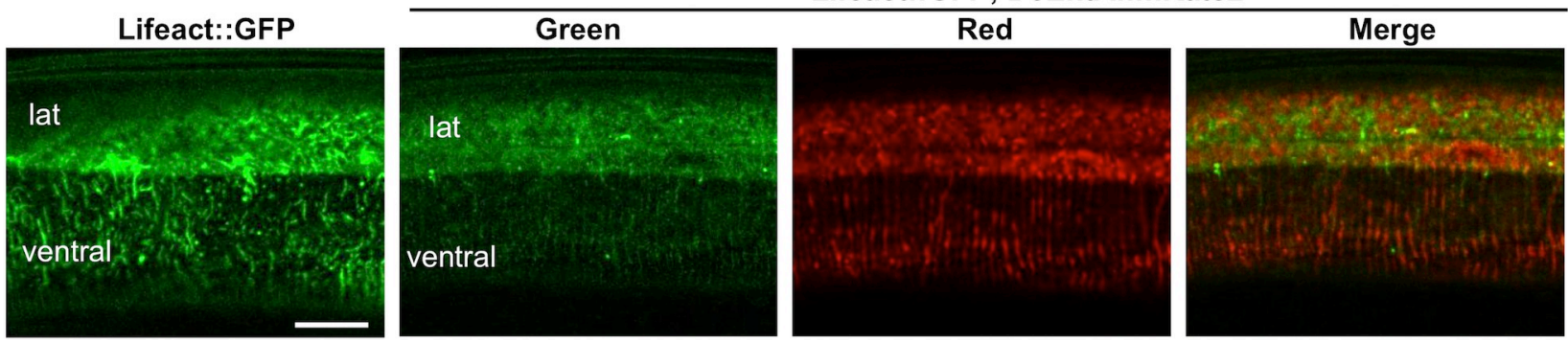

Fig 6. DcEntA interacts with many candidate host proteins and disrupts endocytosis and the host cytoskeleton. (A) The relative abundance of proteins co-precipitated with DcEntA::FLAG::Degron::mKate2 was assessed by mass spectrometry. Volcano plot showing specific interaction partners (in red) of DcEntA::FLAG::Degron::mKate2 (DcEntA in blue). The mean values for fold change from 3 independent experiments are shown. The SAM (significance 
analysis of microarrays) algorithm was used to evaluate the enrichment of the detected proteins. Proteins that met the combined enrichment threshold (hyperbolic curves, $t_{0}=2$ ) are coloured in red. The 2 C. elegans ARF proteins are shown in brown, known members of the nuclear pore complex (NPP) are in green, eukaryotic initiation factor proteins (eIF) in purple and proteins corresponding to Nipi (No Induction of Peptide after Drechmeria Infection) genes in orange. (B) Confocal images of young adult worms expressing RAB-5::GFP together with DcEntA::mKate2 (IG2022, panels, in order, green, red, and green and red channels together) in the epidermis. Selected instances of DcEntA's colocalisation with RAB-5 are highlighted with arrows. Scale bar $10 \mu \mathrm{m}$ in the upper panel, $5 \mu \mathrm{m}$ in the lower panel. (C) Confocal images of young adult worms expressing RAB-5::GFP together with DcEntA::mKate2 (IG2022, right-hand panels, in order, green, red, and green and red channels together) in the epidermis, and their siblings without the DcEntA transgene (left panel). When DcEntA expression is higher, some RAB-5 signal becomes diffuse in the cytoplasm of the lateral epidermis (lat), colocalising with DcEntA (arrow). (D) Confocal images of young adult worms expressing ERM-1::mNG together with DcEntA::mKate2 (IG2051, right-hand panels, in order, green, red, and both channels together) in the epidermis, and their siblings without the DcEntA transgene (left panels). When DcEntA expression is low (upper panels), some ERM-1 is still observed in a fibre pattern, as well as with a localisation at the junction with the seam cell, co-localised with DcEntA (arrow). When DcEntA expression is higher, (lower panels), the ERM-1 pattern becomes diffuse at the seam cell (sc) boundary and some aggregates can be observed in the cytoplasm, co-localised with DcEntA. Scale bar $10 \mu \mathrm{m}, \mathrm{n}>10$. (E) DcEntA disrupts the actin cytoskeleton. Confocal images of young adult worms expressing Lifeact::GFP together with DcEntA::mKate2 (IG2024, right-hand panels, in order, green, red, and green and red channels together) in the epidermis, and their siblings without the DcEntA transgene (left panel). Scale bar $10 \mu \mathrm{m}$.

https://doi.org/10.1371/journal.pgen.1009600.g006

The list of candidate DcEntA interactors also included several proteins involved in cytoskeleton dynamics, including the nematode ezrin/radixin/moesin (ERM) orthologue ERM-1, the microtubule plus-end binding protein EBP-1, and the twinfilin homologue TWF-2, an actin binding protein. One of the main functions of ERM proteins is to link the plasma membrane and the actin cytoskeleton. We observed ERM-1 in randomly orientated fibres in the lateral epidermis, consistent with its reported localisation in other epithelial tissues in C. elegans [77], and increased at the baso-lateral junction with the seam cell (Fig 6D, left panel). When DcEntA expression was low, we observed a partial colocalisation with ERM- 1 at the junction with the seam cell. When DcEntA expression was high, the normal pattern of ERM-1 in fibres was disrupted, the two proteins co-localised in aggregates in the cytoplasm. Additionally, the normal specific localisation of ERM-1 in hyp7 at the baso-lateral junction with the seam cell was replaced by a diffuse expression over the entire surface of contact between the 2 cells (Fig 6D, upper and lower panels respectively, $\mathrm{n}>10$ worms). DcEntA expression also disrupted the actin cytoskeleton, including the prominent cortex underneath the muscle (Fig 6E). Coordinated changes in microtubule and actin dynamics are required for the proper recruitment of SNF-12 to sites of injury in hyp7 [49]. There are thus several potential ways that DcEntA could influence the localisation SNF-12.

There were also 6 NPP proteins, components of the nuclear pore, required for nucleocytoplasmic transport, and at least 5 involved in translation initiation. Two of each category (NPP-1 and NPP-6; EIF-2gamma and F33D11.10, respectively) had previously been implicated in the regulation of AMP gene expression: the 4 corresponding genes were identified in a whole-genome RNAi screen for positive regulators of $n l p-29$ expression, and are thus Nipi (No Induction of Peptide after Drechmeria Infection) genes [43]. Another 8 candidate DcEntA interactors correspond to Nipi genes (Fig 6A and 54 Table). Thus, it is possible that DcEntA has multiple modes of action: affecting translation, altering endocytosis and the cytoskeleton, as well as blocking nuclear import of STA-2 via an effect on SNF-12 and/or alteration of nuclear pores (see model below).

\section{DcEntB affects nucleolar size and shape}

Turning to DcEntB, as described above, it localises to the nucleolus. Nucleoli are the site of ribosome biogenesis and also play a role in cells' responses to diverse stresses [78]. They have been linked to the regulation of immune responses against bacterial pathogens in C. elegans $[79,80]$. Interestingly, we observed a clear alteration of nucleolar morphology in worms expressing DcEntB, with many nucleoli exhibiting strikingly angular shapes rather than their usual spherical form (Fig 7A and 7B). This is reminiscent of the morphological changes that 
A

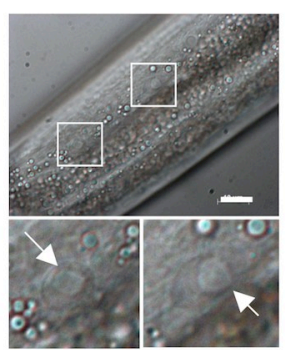

B

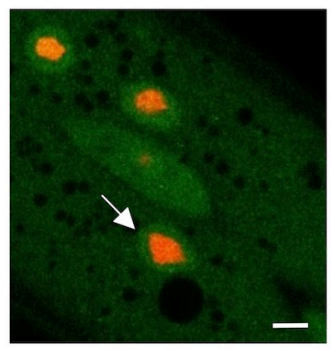

C

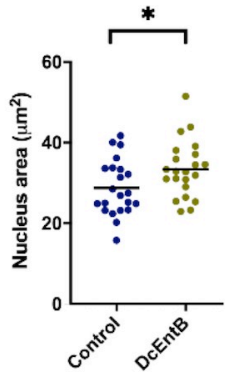

D

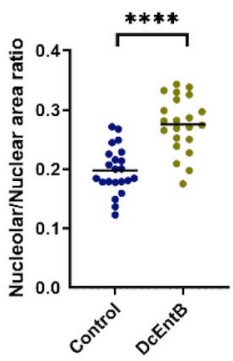

E

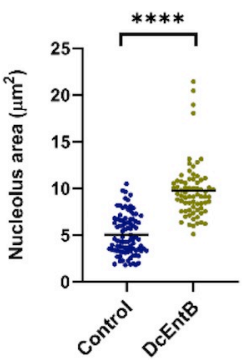

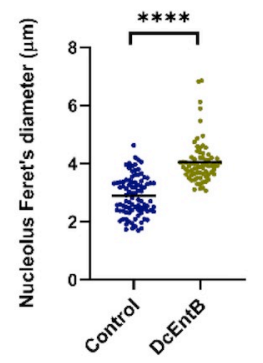

F

FIB-1::GFP
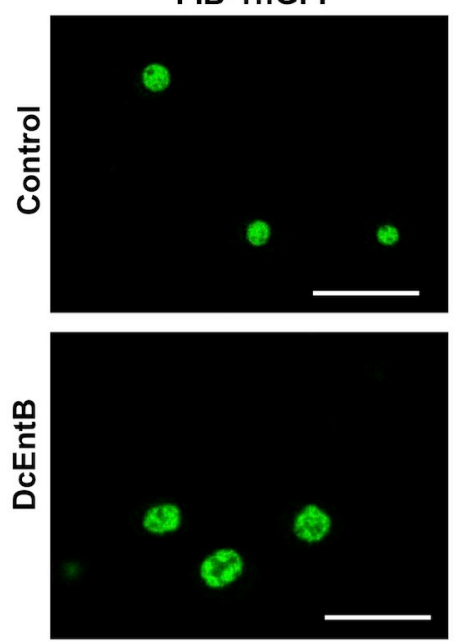

BFP-NLS
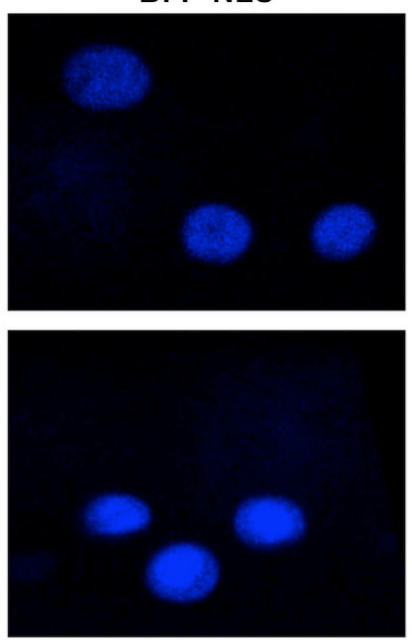

DcEntB::mKate2
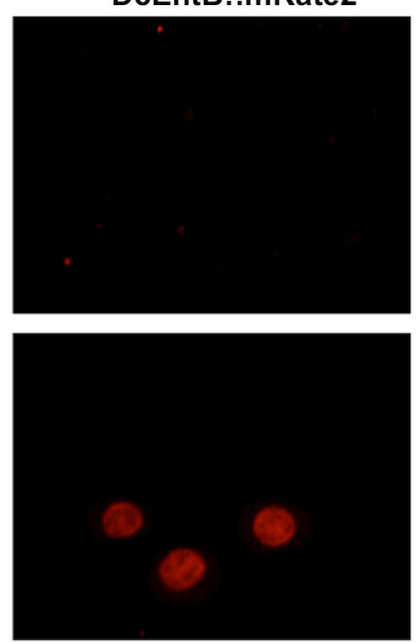
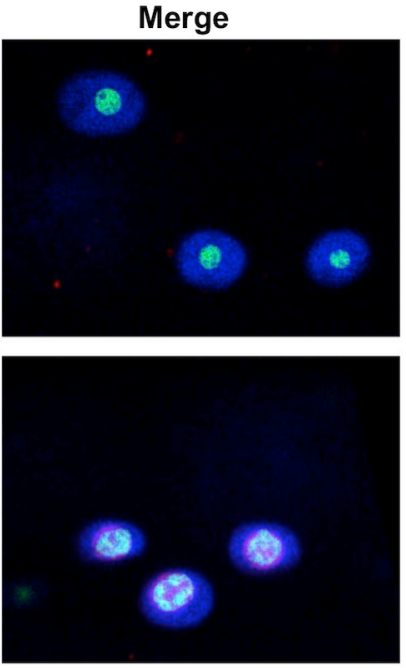

Fig 7. DcEntB makes nucleoli irregular and larger. (A) Representative Nomarski image of a young adult worm expressing DcEntB::mKate2. Scale bar, $10 \mu \mathrm{m}$. Enlarged views of the boxed regions show the large and irregular nucleoli (white arrows). (B) Representative confocal image of a young adult worm expressing DcEntB::mKate2 and STA-2::GFP (IG1977) in hyp7. White arrow points to an irregular nucleolus (red). Scale bar, $10 \mu \mathrm{m}$. (C, D) Quantification of nuclear size (C) and nucleolus/nucleus ratio (D) in the epidermis of young adult IG1977 worms (DcEntB) and their siblings without the DcEntB transgene (Control). $\mathrm{n}>20$ in each strain; bars represent the mean; ${ }^{*} \mathrm{p}<0.05$, unpaired t-test ${ }^{* * * *} \mathrm{p}<0.0001$, unpaired t-test. (E) Quantification of nucleolus area and Feret's diameter in hyp7 of young adult worms expressing FIB-1::GFP together with (DcEntB; IG1984) or without (Control; IG1596) DcEntB. ${ }^{* * * *} \mathrm{p}<0.0001$. Statistical significance was determined using a nonparametric Mann Whitney test. (F) Confocal images of hyp7 nuclei in young adult worms expressing FIB-1::GFP together with (DcEntB; IG1984; lower panels) or without (Control; IG1596; upper panels) DcEntB. All worms also express BFP-NLS; panels from left to right: green, blue, red, and the 3 channels together, scale bar, $5 \mu \mathrm{m}$.

https://doi.org/10.1371/journal.pgen.1009600.g007

accompany several different pharmacological treatments, including ATP depletion, in mammalian cells [81]. Expression of DcEntB was associated with an increase in nuclear size (Fig 7C), and a proportionately larger increase in the size of nucleoli (Fig 7D). We also used the FIB-1::GFP reporter [37] to characterise and quantify these changes, and confirmed a highly significant increase in nucleolus size and Feret's diameter. The latter is a measure of the longest distance between any two points along the nucleolar boundary and when compared to area gives an indication of any deviation from circularity (Figs 7E and 7F and S10A). This suggests that DcEntB will have a direct effect on nucleolus biology.

\section{DcEntB increases AMP gene expression and can prime the immune system}

In direct contrast to the effect of DcEntA, expression of DcEntB was associated with an increase in the constitutive expression of the $n l p-29 p:: G F P$ reporter (Fig 8A). This increase was dependent upon STA-2 since sta-2(RNAi) reduced reporter gene expression back to the normal level (Fig 8B). Using qRT-PCR, we confirmed the positive effect of DcEntB on $n l p-29$ 
A

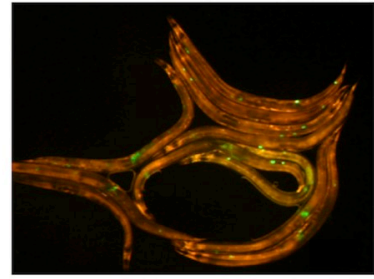

DcEntC; frls7

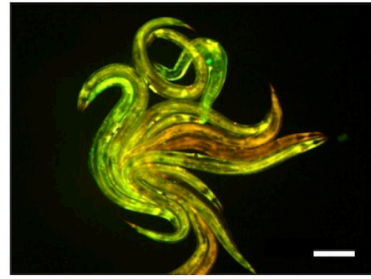

DcEntB; frls7

B

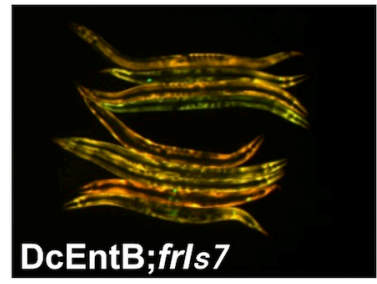

RNAi:

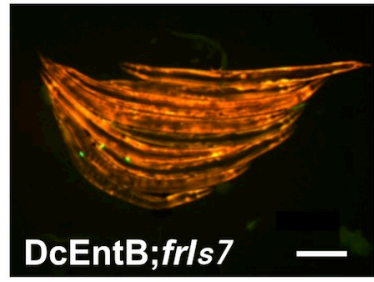

sta-2
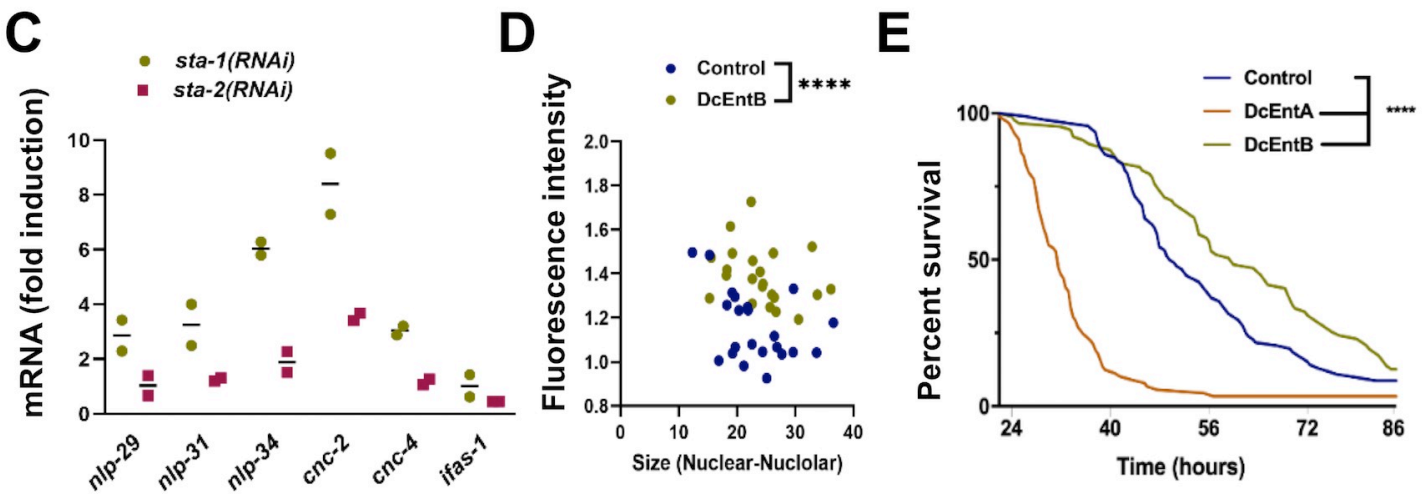

F

Fig 8. DcEntB induces AMP gene expression in a sta-2-dependent manner. (A, B) Representative images of adult worms, 3 days after the L4 stage, carrying frIs7 and expressing DcEntC (IG1883) or DcEntB (IG1941) on E. coli OP50 (A) or following RNAi against sta-1 or sta-2 (B). frIs7 includes $n l p-$ 29p::GFP and col-12p::dsRed transgenes; red and green florescence is visualized simultaneously. Scale bar, $200 \mu \mathrm{m}$. A difference in GFP levels for worms with frIs7 between OP50 and RNAi (HT115) bacteria has been observed regardless of the genetic background. (C) Quantitative RT-PCR analysis of the expression of $n l p, c n c$ and ifas-1 genes in worms expressing DcEntB (IG1941) following RNAi against sta-1 or sta-2. Results from 2 independent experiments are shown relative to the expression levels in age-matched control (hygR:frIs7 IG1864) worms. (D) Intensity of green fluorescence in the nuclei of DcEntB;STA-2::GFP worms (DcEntB, IG1977, green), and their siblings without the DcEntB transgene (Control, blue), plotted against the nuclear-nucleolar size, measured using ImageJ. Each dot represents a nucleus; $\mathrm{n}>20$, ${ }^{* * * *} \mathrm{p}<0.0001$, unpaired t-test. (E) Survival of control (IG1864) worms and worms expressing DcEntA (IG1942) or DcEntB (IG1941) after infection as young adults with a concentration of D. coniospora spores 10 times higher than usual at $25^{\circ} \mathrm{C}(\mathrm{n}=92,91$ and 87 respectively $) .{ }^{* * * *} \mathrm{p}<0.0001$, one-sided log rank test. The curves here are representative of 2 independent biological replicates for which the ratio of median survival (TD50) between worms expressing DcEntA or DcEntB to control worms are shown in (F).

https://doi.org/10.1371/journal.pgen.1009600.g008

expression, and demonstrated a similar sta-2-dependent effect for several $n l p$ and $c n c$ genes (Fig 8C). Notably, worms expressing DcEntB did not exhibit any change in ifas-1 expression (Fig $8 \mathrm{C}$ ). Together, these results suggest that DcEntB might act through the canonical STA-2 pathway to regulate AMP gene expression. Supporting this, when we crossed the DcEntB transgene into a strain expressing STA-2::GFP, we observed a significant increase in the amount of STA-2::GFP in the nucleus (Fig 8D).

There is therefore a striking dichotomy between the effects of DcEntA and DcEntB. DcEntA appears to act as many known virulence factors do, blocking the activation of an immune defence pathway, in this case potentially via an inhibition of the activity of the transcription factor STA-2. DcEntB, on the other hand, appears to activate the same pathway, leading to more STA-2 in the nucleus and more AMP gene expression. We hypothesised that this might reflect a host defence strategy wherein the presence of DcEntB is detected, either directly or indirectly, as a form of surveillance immunity. Should this be the case, one would predict that expression of DcEntB might increase survival following infection. Although we showed that following infection under standard conditions DcEntB-expressing worms had an increased susceptibility to infection (Fig 2D), when we infected the same strain of worms with D. coniospora using a very high concentration of spores, in contrast to worms expressing DcEntA that died more rapidly, the DcEntB-expressing worms were indeed significantly 
resistant, and lived longer even than the controls (Fig 8E and 8F). Thus, presumably as a consequence of its complex effect on gene expression and the dynamics of the infection process, depending on the infectious burden, DcEntB can have positive or negative effects on resistance to infection. Nevertheless, the presence of high levels of DcEntB does appear to have the capacity to prime the host immune system.

\section{DcEntB-induced changes in nucleolar morphology require STA-2 and are associated with a specific induction of targets of the p38 MAPK pathway}

To investigate the link between the observed changes in STA-2 nuclear occupancy, AMP gene expression and nucleolar morphology, we first assayed whether sta-2(RNAi) affected the shape of nucleoli, using the FIB-1::GFP reporter strain. In contrast to control worms, upon sta-2 inactivation, we observed a very marked decrease in the DcEntB-associated nucleolar phenotypes, both size and Feret's diameter (Figs 9A and S10B), suggesting that the change in nucleolar morphology could be a consequence of DcEntB's recruitment of STA-2 to the nucleus and/ or the resulting STA-2-dependent changes in gene expression. Notably, when we quantified nucleolar morphology in the FIB-1::GFP reporter strain infected with $D$. coniospora, we observed a modest increase in size relative to uninfected controls, without a significant change in Feret's diameter (Figs 9B and S11A).

To explore further the relationship between nucleolar morphology and the sta-2-dependent immune response, we treated worms carrying FIB-1::GFP with CHX that, in addition to affecting protein synthesis, is also known to alter nucleolar shape [81]. Exposure of adults to $500 \mu \mathrm{g} / \mathrm{ml} \mathrm{CHX}$ for $6 \mathrm{~h}$ caused nucleoli to become larger and less round (Figs 9C and 9D and S11B). Additionally, it led to a modest but significant increase in the expression of the $n l p-$ 29p::GFP reporter (Fig 9E). Using qRT-PCR, we confirmed this effect on $n l p-29$ expression, and demonstrated a similar effect for $n l p-34$ (Fig 9F), albeit to a lesser degree than irg-1, which responds strongly to CHX treatment (Fig 5F; [57]). Notably, the expression of $c n c-2$ and $c n c-4$ was not affected by exposure to CHX (Fig 9F). These 2 genes are not regulated by p38 MAPK PMK-1 upon D. coniospora infection [40]. When we crossed the DcEntB-expressing strain with a strain carrying the atf-4p(uORF)::GFP reporter, we observed a large increase in GFP expression in adult worms (Fig 9G), consistent with an inhibitory effect of DcEntB on protein synthesis. Taken together with the fact that DcEntB does not increase the expression of ifas-1 (Fig 8C), but CHX treatment does (Fig 5E), these results suggest that the potential inhibition of protein synthesis by DcEntB leads to a specific induction of a p38 MAPK dependent immune response in the epidermis, in addition to its more direct effect on STA-2 activity. The action of DcEntB can be contrasted with the model for the effects of DcEntA that, directly or indirectly, prevents accumulation of STA-2 in the nucleus and thereby inhibits the expression of multiple defence genes, rendering C. elegans more susceptible to infection. At the same time, potentially as a counter-defensive mechanism, loss of STA-2-dependent repression accentuates the increase in the expression of ifas-1 provoked by $D$. coniospora, and presumably of other host genes that potentially help protect against infection and that are induced following a reduction in translation (Fig 10).

\section{DcEntB potentially interacts with many host proteins to affect diverse aspects of host cell physiology}

In an attempt to understand better the complex effects of DcEntB we undertook the same type of biochemical approach as described above for DcEntA, in the hope of finding meaningful protein partners. We identified 121 proteins as being specifically enriched in the proteins coimmunoprecipitated with DcEntB (S5 Table). One of them, NST-1, is the orthologue of 
A

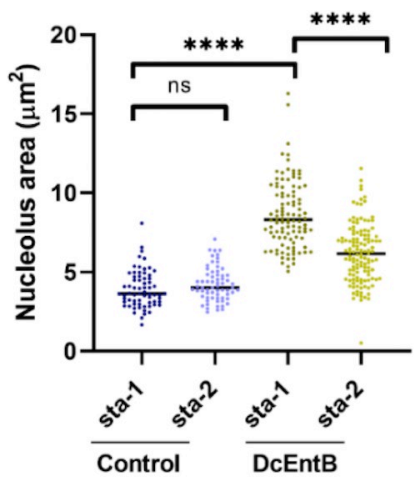

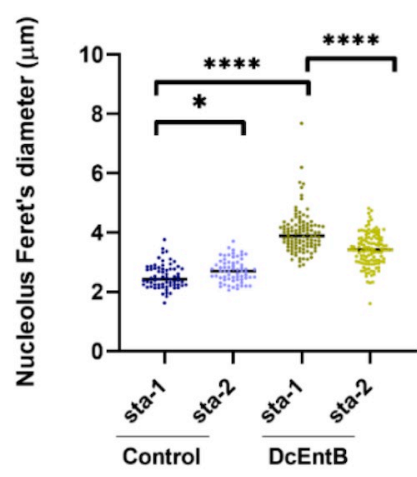

B

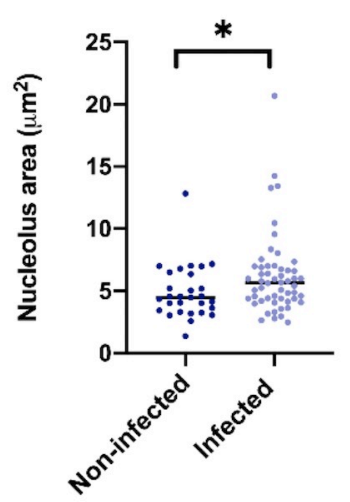

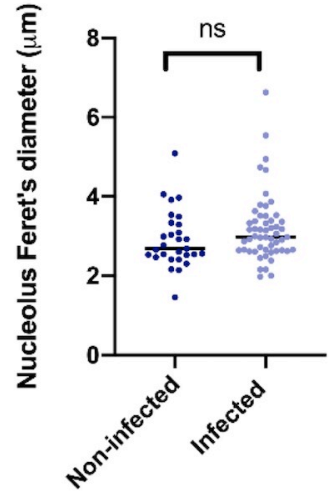

C
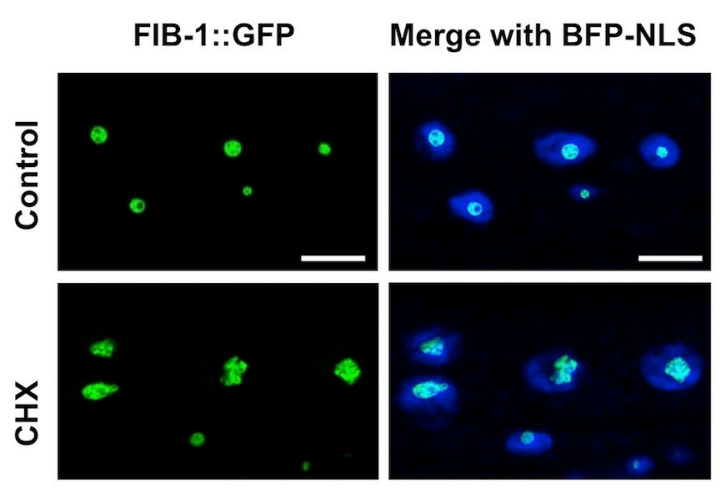

E

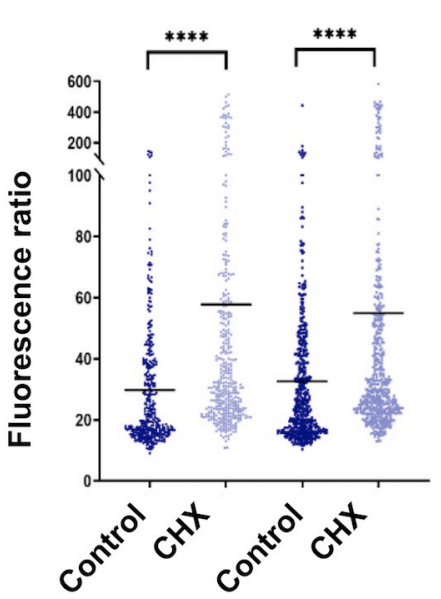

$\mathbf{F}$

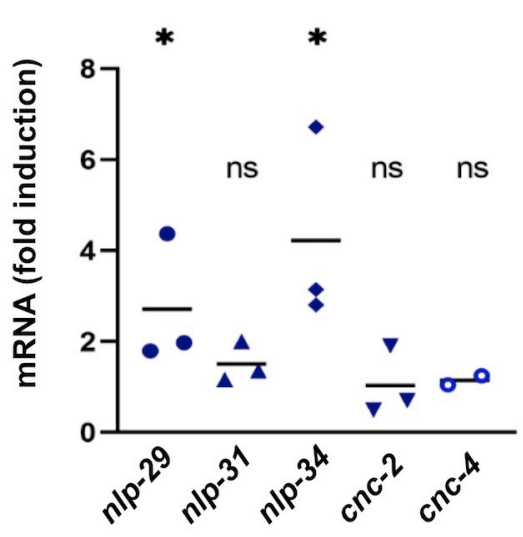

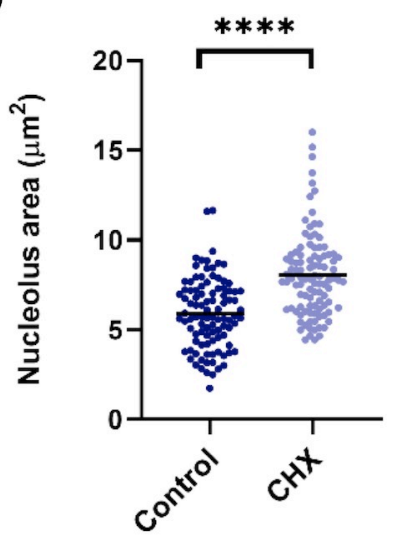

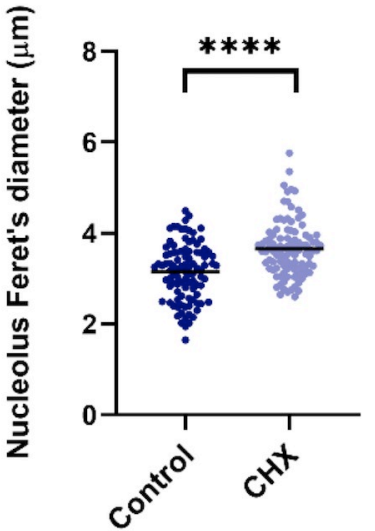

G

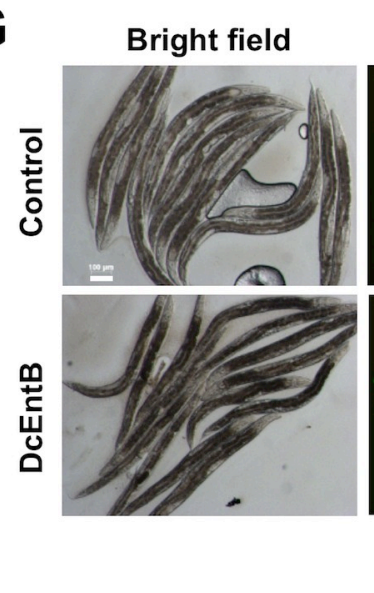

atf-4(UORF)p::GFP

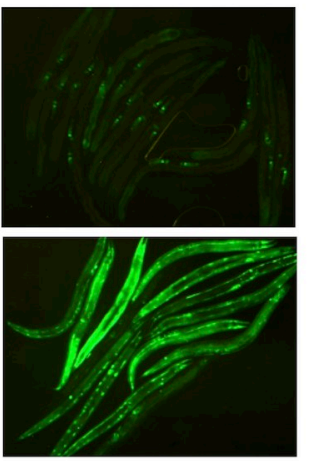

Fig 9. Relationship between nucleolar morphology, translation and AMP gene expression. (A, B) Quantification of nucleolus area and Feret's diameter in young adult worms expressing FIB-1::GFP together with (DcEntB; IG1984) or without (Control; IG1596) DcEntB following RNAi against sta-1 or sta-2 (A) or in IG1596 worms following $24 \mathrm{~h}$ infection (B). (C) Representative confocal images of young adult IG1596 worms (that express BFP-NLS in addition to FIB-1:: GFP) after exposure for $6 \mathrm{~h}$ to cycloheximide (CHX; lower panels) compared to control (upper panels); left and right panels: green, and green and blue channels together, respectively), scale bar, $5 \mu \mathrm{m}$. (D) Quantification of nucleolus area and Feret's diameter in young adult worms expressing FIB-1::GFP (IG1596) after exposure for $6 \mathrm{~h}$ to CHX, compared to control untreated worms. (E) Quantification of relative green fluorescence of young adult worms carrying frIs7 ([nlp-29p::GFP; col-12p::dsRed]; IG274) after exposure for $6 \mathrm{~h}$ to CHX, compared to control untreated worms. The results from 2 independent experiments are shown. (F) Quantitative RT-PCR analysis of the expression of $n l p$ and $c n c$ genes in worms carrying frIs7 (IG274) following exposure as young adults to CHX for $6 \mathrm{~h}$. Results from 3 independent experiments are shown as averages with standard deviation, relative to the expression levels in age-matched control worms. Statistical significance was determined using a nonparametric Mann Whitney test; ${ }^{*} \mathrm{p}<0.05,{ }^{* * * *} \mathrm{p}<0.0001$, ns, not significant. (G) Representative images (left panels: white light, right panels: green fluorescence) of one day old adult worms carrying an atf-4p(uORF)::GFP reporter also expressing DcEntB (IG2045; bottom panels), and their siblings without the DcEntB transgene (upper panels). Scale bar, $200 \mu \mathrm{m}$.

https://doi.org/10.1371/journal.pgen.1009600.g009 


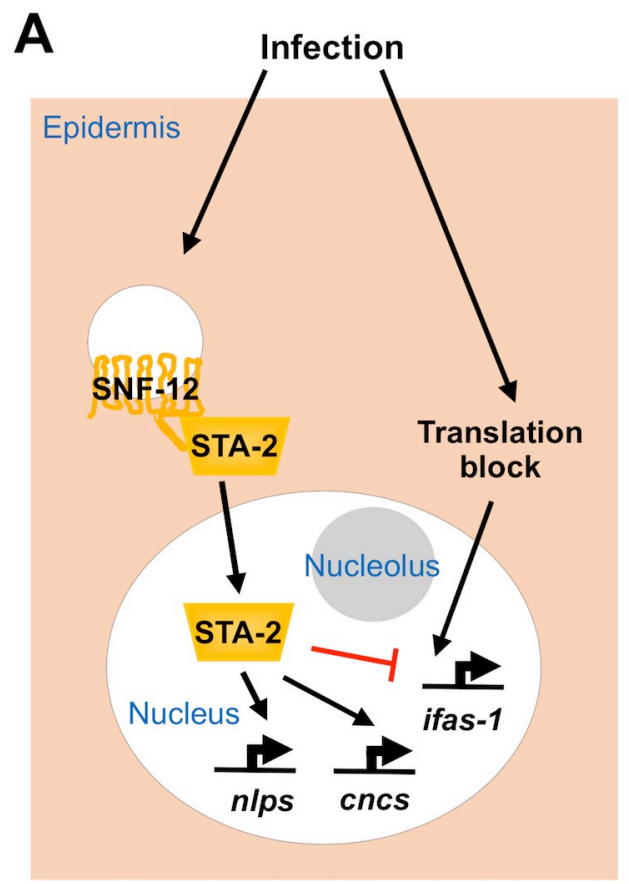

B DcEntA

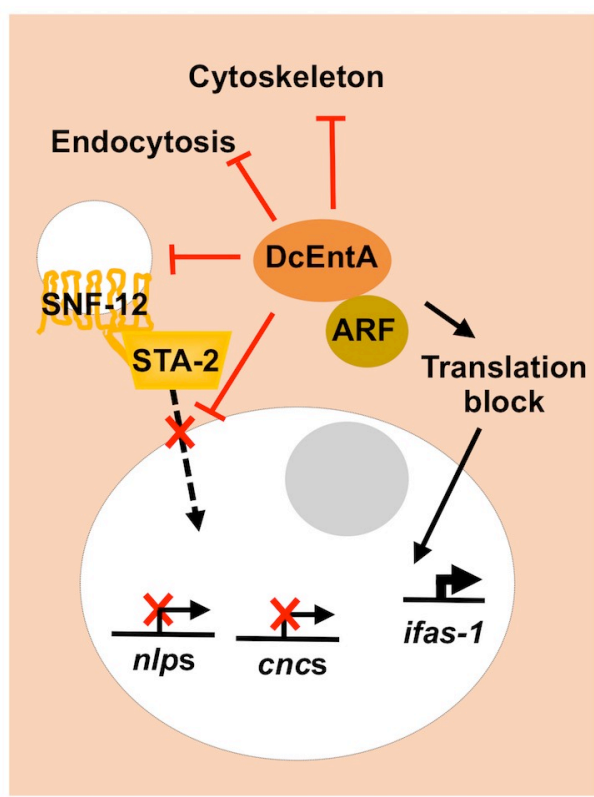

C

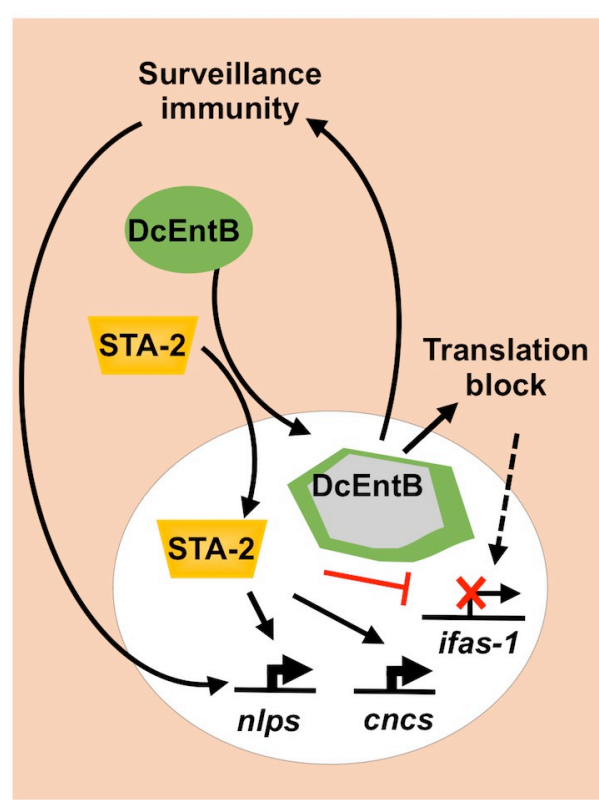

Fig 10. Models of the innate immune response to $D$. coniospora infection and the action of DcEntA and of DcEntB. (A) Infection by D. coniospora activates a pathway involving SNF-12 and STA-2. The translocation of STA-2 into the nucleus leads to an increase in the expression of $n l p$ and $c n c$ genes. An uncharacterized parallel pathway, potentially linked to surveillance of translation, activates ifas-1, which is negatively regulated by STA-2. (B) DcEntA, via its interaction with host ARF GTPases and other protein partners (brown circle), through ADP ribosylation, potentially interferes with the normal innate immune response at multiple levels. It alters SNF-12 localization, blocks STA-2 nuclear translocation and AMP gene expression. It inhibits translation, leading to an increase in ifas-1 expression, accentuated by the loss of the repressive function of STA-2. DcEntA interferes with endocytosis, disrupts the cytoskeleton and causes increased cuticle fragility, potentially further increasing susceptibility to infection. (C) When DcEntB is expressed in hyp7, it localises to the nucleolus. Expression of DcEntB drives STA-2 into the nucleus, leading to an increase in $n l p$ and $c n c$ gene expression and suppressing ifas- 1 expression. DcEntB alters the shape and size of the epidermal nucleoli. This provokes a surveillance mechanism leading to the expression of $n l p$ but not $c n c$ genes.

https://doi.org/10.1371/journal.pgen.1009600.g010

human GNL3L ( $G$ protein nucleolar 3 like), a nucleolar GTPase that is essential for ribosomal pre-rRNA processing and cell proliferation [82]. As mentioned above, many heat-labile enterotoxins exert their effects through ADP-ribosylation of guanine nucleotide-binding proteins. Among the other candidate DcEntB interactors that are predicted by NoD NoLS predictor [33] to be nucleolar proteins (S5 Table), PES-7/IQGAP, LET-60/HRas, RAB-6.1/RAB6A and CDC-42/CDC42 all have GTP binding or GTPase activity. Interestingly, the homologue of LET-502, the Rho-associated coiled-coil kinase, ROCK1, was recently shown to concentrate in the nucleolus during human cytomegalovirus infection [83]. Whether these different candidates are authentic interactors of DcEntB remains, however, to be established.

One of the consequences of DcEntB expression is an increase in nlp-29p::GFP reporter gene expression. In a previous genome-wide RNAi screen for this same phenotype, we identified close to 300 genes [43]. Among the corresponding proteins, only 2 (SEM-5 and K08E3.5) correspond to candidate DcEntB interactors. DcEntB, in common with DcEntA, also appears to inhibit translation. Several of its potential interactors (e.g. CIF-1 and IFG1, eukaryotic translation initiation factor orthologues) are essential components of the translational machinery. As none of these proteins are predicted to be nucleolar (S5 Table), the relevance of these observations remains to be established.

To take a broader view, we again used the enrichment tools in Wormbase. In contrast to the DcEntA interactors, there were few enriched classes. Among them, "nuclei enlarged" (WBPhenotype:0001567; $\mathrm{p}=7.4 \times 10^{-4}$ ) stood out, with both LET-502/ROCK and LET-60/HRas 
associated with this term ([84]; S5 Table). Given the alteration of nuclear size and nucleolar morphology provoked by DcEntB expression, these candidates merit further investigation. As knocking down the gene corresponding to one other candidate protein with this annotation, RNP-4, (orthologue of human RBM8A (RNA binding motif protein 8A) causes a block in AMP gene expression [43], understanding precisely the consequences of DcEntB expression will be challenging. It would be facilitated by identifying those host proteins that are not only interactors of DcEntB but also substrates for its enzymatic activity. For the time being, we did not find convincing evidence for specific ADP-ribosylation of any of the candidate enterotoxin interactors. ADP-ribose is a labile group that breaks easily with the fragmentation method used for the mass spectrometric analysis [85]. Nevertheless, the results reported here represent an important step in understanding the complexity of the molecular interactions that underlie D. coniospora's capacity to infect and kill C. elegans.

\section{Discussion}

The comprehension of fungal pathogenesis requires the identification of virulence factors and a dissection of their mode of action. In the current study, we chose to express individual candidate fungal virulence factors, as tagged chimeric proteins in a single tissue, the multi-nuclear epidermal syncytium hyp7. Tagging proteins can affect their sub-cellular localisation and/or function [86,87]. There has, however, been sufficient experience with fluorescent reporter proteins, in C. elegans and in other model organisms, including genome-wide surveys of protein localization [88], to know that in most cases the chimeric protein acts like its unmodified counterpart. Our approach is analogous to a recent study where numerous candidate secreted effector proteins from the plant pathogen Colletotrichum higginsianum were expressed as N-terminal fusions with GFP directly inside plant cells and determined to localize to peroxisomes, Golgi bodies, and microtubules [89]. As another example, a putative virulence factor from the nematode-trapping fungus Duddingtonia flagrans was expressed in C. elegans as a C-terminal GFP-fusion construct where it is localized to nuclei, consistent with the presence of an NLS in its sequence [90]. Among the D. coniospora proteins we studied here, DcEntB had a nucleolar localization, as predicted in silico. Generally, therefore, the expression pattern of a chimeric protein will reflect that of the native protein. In cases where more than one virulence factor act in a complex, however, expressing them individually may not be predictive of their behaviour during a natural infection. Further, the actions of some virulence factors may be antagonistic, as seen for the effect of DcEntA and DcEntB on AMP gene expression, so alone their effects will not reproduce the natural pathophysiology of infection. Nevertheless, when, as here, mutants are not available, heterologous expression can provide one route to understanding virulence factor function under conditions that are more physiological than ex vivo or in vitro systems.

Dozens of the D. coniospora proteins predicted to be secreted are lineage-specific [2] and presumable result from co-evolution with nematode hosts. They are of great interest for the understanding of evolutionary dynamics, for which D. coniospora is potentially a powerful model [11], but represent a major challenge due to the lack of any prior knowledge. Therefore, here, we chose to focus on enterotoxin genes that are expected to play a direct role in fungal virulence. We selected 3 from the expanded genomic repertoire of $D$. coniospora genes encoding enterotoxin $\alpha$ domain proteins. Expression of one of them, DcEntC was not associated with strong phenotypes, and did not reduce the lifespan of $C$. elegans. This indicates that the effects of DcEntA and DcEntB, which made worms sick and die precociously are specific. They presumably reflect the functions of their auxiliary protein domains. This was consistent also with their unique sets of potential host protein targets. Whether $D c E n t C$ expression impacts resistance to infection has yet to be established. 
We observed that DcEntA, disrupted the actin cytoskeleton and the normal vesicular pattern of SNF-12, prevented the accumulation of STA-2 in the nucleus and blocked AMP gene expression. We recently demonstrated that upon wounding, microtubule rearrangement drives reorganisation of the actin cytoskeleton and is required for proper recruitment of SNF12 to the injury site, as well as STA-2-dependent AMP gene expression [49]. Thus, DcEntA may inhibit AMP gene expression through an effect on SNF-12 localisation and STA-2 activity. Blocking key immune defence pathways is a strategy used by many pathogens across kingdoms [91-93].

The gene ifas- 1 is induced upon D. coniospora infection. We found that this is potentially a consequence of translation inhibition, and that suppressing STA-2 activity promoted ifas-1 expression. While the precise pathway that positively regulates ifas- 1 is currently unknown, this effect could be seen as a fail-safe surveillance mechanism, whereby fungal interference with a major defence pathway leads to a boost of a complementary defence mechanism.

Both DcEntA and DcEntB appear to reduce translation. Many enterotoxin $\alpha$ proteins ADP-ribosylate elongation factor family (EF2) proteins essential for ribosome function. Notably, Exotoxin A from P. aeruginosa targets EF2, thereby blocking protein synthesis in C. elegans intestinal epithelial cells $[57,58]$. It is possible that DcEntA and DcEntB also act at the translational level, impacting host defence protein expression as, while not finding EF2 proteins, we noted several eukaryotic Initiation Factor (eIF) proteins among the specific interactors of both DcEntA and DcEntB. While DcEntA decreases STA-2 levels in the nucleus, which has the potential to boost ifas- 1 expression, DcEntB increases them, potentially explaining why it does not induce ifas-1 expression (Fig 10).

Interestingly, given the pattern of SNF-12 observed upon expression of DcEntA, with an enrichment along the baso-lateral seam cell boundary, 38 of the high-confidence DcEntA interactors are known to be potential binding partners of DLG-1, which is found in the same location [75]. We also identified 11 proteins reported to interact with AKIR-1, which is essential for AMP gene expression in hyp7 [42], suggesting an additional way in which DcEntA might affect the host response. Together our results indicate that DcEntA affects, directly and indirectly, host defence protein expression, by targeting different cellular processes. This is not unusual for virulence factors, with, for example, EspF from enteropathogenic and enterohemorrhagic Escherichia coli described as a "bacterial pathogen's Swiss army knife" because of the diversity of its actions [94]. Further study will be required to validate the many candidate host protein interactors and to determine whether any have preponderant roles in pathogenesis during a normal infection.

The effect of DcEntB expression was also complex. One prominent consequence was an increase in AMP gene expression, dependent on the canonical STA-2 pathway. DcEntB was concentrated in the nucleolus, a dynamic sub-nuclear organelle for ribosomal RNA (rRNA) biogenesis that acts as a cellular stress sensor [95]. For example, impairment of nucleolar function is thought to stabilize p53, a key regulator of cellular homeostasis [96], while inhibition of proteasome activity leads to sequestration of $\mathrm{p} 53$ proteins to the nucleolus [97]. In C. elegans, the p53 homologue, CEP-1, acts downstream of NOL-6, a nucleolar RNA-associated protein (NRAP), via its transcriptional target SYM-1 to enhance resistance to bacterial infection [80]. More recently, it was shown that infection by P. aeruginosa decreases the level of the nucleolar pre-rRNA processing protein fibrillarin, FIB-1 [79]. FIB-1 acts downstream of the BRAT/TRIM2 homologue, NCL-1, to regulate rRNA abundance and nucleolar size [37]. Bacterial infection therefore decreases rRNA and nucleolar size [79]. For the moment, no P. aeruginosa effector has been found to localise specifically to the host nucleolus. Indeed, it was only comparatively recently that examples of bacterial effectors that target the nucleolus were identified, the first being EspF [98]. Here, we found that DcEntB is recruited to nucleoli 
and can make them larger and irregularly shaped. This is also one of the consequences of infection of the epidermis by $D$. coniospora, but whether this depends solely on the action of DcEntB remains to be established. The relationship between the change in nucleolar morphology and the expression of AMP genes appears complex. On the one hand, blocking protein translation, which alters the nucleolus, was associated with a small and specific increase in $n l p$ AMP gene expression. On the other, knocking down sta-2 expression blocked the elevated AMP gene expression induced by DcEntB and reverted nucleoli almost to normal. Further work will be needed to tease out the underlying causal links.

Regardless, this induction of AMPs could be interpreted as a type of surveillance immunity. Potentially, the changes in cellular physiology provoked by DcEntB could be detected as a damage signal and induce an immune response in the epidermis (Fig 10). Several other examples illustrate the important role of surveillance immunity in C. elegans (reviewed in [99]). In one case, Stx1, a virulence factor from enterohemorrhagic E. coli that is able to inhibit protein synthesis, activates the intestinal p38 MAPK pathway [100]. Apart from the core MAPK cassette that is shared between epidermis and intestine, the p38 pathway has distinct inputs and outputs in the two tissues (reviewed in [101]). It has been shown, however, that there is an intimate balance of MAPK activity between the 2 tissues, with stimulation of the p38 pathway in one negatively influencing its activity in the other [43], via a mechanism potentially involving the Tribbles homologue NIPI-3 [41,102]. Thus, while we expect virulence factors like DcEntA and DcEntB to act in a cell autonomous manner, during the course of an infection, they also have the potential to influence immune defences in distant tissues. During infection, as mycelia spread, virulence factors would be secreted into different tissues, and potentially into the pseudocoelom. This further complicates any understanding of the dynamic host response to natural infection.

It is interesting to note that in contrast to DcEntA that has a unique C-terminal domain not found in any other protein, DcEntB has orthologues in many pathogenic fungi. These include in nematode-trapping fungi Dactylellina spp. [103] and Drechslerella spp. [104], as well as the egg-infecting species Pochonia chlamydosporia [105]. The different species represent distinct branches on the phylogenetic tree, reflecting the multiple independent origins of nematode parasitism [2]. Orthologues are also found in ant-infecting Ophiocordyceps species [106]. It has previously been suggested that heat-labile enterotoxins are important effectors in host adaptation and co-evolution [107]. It is possible that as a more ancient virulence factor, C. elegans has been able to develop a counter-defensive strategy against DcEntB. This would then potentially drive enterotoxin diversification in D. coniospora, leading to the emergence of DcEntA. We hypothesise that C. elegans has not yet evolved an effective defence strategy against this more recent virulence factor. It will clearly be important in the future to assay the expression of the different enterotoxin genes, measure the levels of the corresponding proteins in C. elegans during an infection, and to gauge their relative importance in pathogenesis, for example by co-expressing more than one factor at a time, all of which is beyond the scope of the current study.

In conclusion, through this initial investigation of $D$. coniospora virulence factors, we have revealed the very complicated, sometimes antagonistic, nature of some of the molecular interactions that come into play during natural fungal infection of $C$. elegans. In addition to providing insight into the molecular function of two representative enterotoxins, we have gained a new understanding of host defence mechanisms.

\section{Supporting information}

S1 Fig. (A, B) Schematic representation of different culture and selection procedures. (A) Transgenic worms carrying $r p s-0 p:$ hygR conferring hygromycin resistance together with unc- 
122p::GFP as an extrachromosomal array (IG1864) were grown on NGM plates supplemented with hygromycin (left) or on standard NGM plates after manual selection on the basis of the expression of the fluorescent marker. (B) IG1864 worms were cultured overnight in liquid in the presence (left) or absence of hygromycin. Worms were transferred to NGM plates and in the latter case selected manually, as above. (C) Quantitative RT-PCR analysis comparing the expression of irg-1 in IG1864 worms selected by growth on hygromycin-supplemented NGM plates to that in worms selected manually (-), and in IG1864 worms selected by synchronization in the presence of hygromycin to that in worms selected manually following synchronization in the absence of hygromycin (+). The results from 2 independent experiments are shown. It can be seen that even in worms that are resistant to hygromycin, prolonged culture in the presence of the antibiotic increases irg- 1 expression, while overnight exposure during early development does not.

(PDF)

S2 Fig. Visualisation of $D$. coniospora genomes highlighting enterotoxin genes. A Circos plot [108] showing the positions of the predicted enterotoxin genes in the genomes of $2 \mathrm{D}$. coniospora strains. The full isolation history of the strains Swe2 (left hand side, derived from ATCC 96282 [2]) and Dan2 (right hand side, ARSEF 6962 [109]) are given elsewhere [11]. Orthologous gene pairs, with their corresponding Genbank protein identifiers, are joined by lines, coloured on the basis of the position on Swe 2 chromosomes. The 3 enterotoxins characterised in the present study are shown in orange and the 4 Dan 2 specific enterotoxin genes are shown in grey. The 4 Swe2 genes with an asterisk were missing from the original gene prediction [2] and were identified by manual curation. The Dan2 gene marked with the asterisk was not originally predicted to encode an enterotoxin [109], but removal of its unique intron gives rise to a bona fide enterotoxin. The Genbank identifiers for the Dan2 chromosomal sequences are shown. Swe2 chromosome 1 is the concatenation of JYHR01000002.1JYHR01000004.1; chromosome 2 of JYHR01000001.1-JYHR01000007.1; chromosome 3 of JYHR01000008.1-JYHR01000009.1-JYHR01000005.1-JYHR01000006.1JYHR01000003.1- JYHR010000011.1-JYHR010000010.1. The numbers on the outside of each chromosome indicate length in $\mathrm{Mb}$. The pattern of gene reorganisation matches exactly the pattern of global chromosomal rearrangements seen between Swe2 and Dan2 [11]. (PDF)

S3 Fig. (A) Expression of enterotoxin genes from the two D. coniospora strains. We re-analysed the available RNAseq datasets for Swe2 and Dan2, to compare expression for the enterotoxin genes from the original Swe2 gene prediction [2] and their Dan2 orthologues. The $\log _{10}$ of the maximal value, expressed as fragments per $\mathrm{Kb}$ of transcript per million mapped reads (FKPM), among the different conditions for each strain is shown. Genes are ranked according to their relative expression in Swe2. DcEntC, DcEntA, DcEntB (from top to bottom) are highlighted in grey. The values for the previously studied gene SapA [2], highlighted in yellow, are shown for comparison. (B) Sequence relationships between the Swe2 enterotoxins. A phylogenetic tree depicting the deduced relationship between all 23 Swe2 enterotoxins. The tree is rooted in its midpoint. Branch confidence is shown for the inner nodes. The scale bar indicates the line length corresponding to one substitution per site. (PDF)

S4 Fig. Quantitative RT-PCR analysis of the relative expression of mKate2 in worms expressing DcEntA (IG1926), or DcEntC (IG1880), relative to those expressing DcEntB (IG1925).

(PDF) 
S5 Fig. (A) Representative images (left panels: white light; right panels: red fluorescence) of two day adult worms expressing DcEntA in a wild-type (IG2043; lower panels) or GPA-12* (IG1926; upper panels) background. Scale bar, $50 \mu \mathrm{m}$. (B) Quantification of the ratio of relative red fluorescence to size (TOF), or of TOF alone (left and right panels, respectively) of two day adult worms expressing DcEntA in a wild-type (IG2043) or GPA-12* (IG1926) background. (C) Lifespan counted from the L4 stage at $25^{\circ} \mathrm{C}$ of control (hygR;frIs 7 IG1864) worms and worms carrying frIs7 expressing DcEntA (IG1942), GPA-12* (IG1389), or GPA-12* and DcEntA (GPA-12*; DcEntA IG1948). For each strain, $\mathrm{n}=50 .{ }^{* * * *} \mathrm{p}<0.0001$, one-sided log rank test. Representative of 2 independent biological replicates. (D) Quantitative RT-PCR analysis of the expression of ifas- 1 in the same 4 strains. Data from two independent experiments are shown. The decrease in ifas-1 expression in IG1389 compared to IG1864 is consistent with previous results [5]. The fold-change in expression level between the 2 indicated conditions is significantly different; ${ }^{*} \mathrm{p}<0.05$, paired one-sided $\mathrm{t}$ test. (PDF)

S6 Fig. (A) Confocal images of young adult worms expressing STA-2::GFP (XW18234) without infection (NI) or $18 \mathrm{~h}$ after infection (Infec) with D. coniospora. Scale bar $20 \mu \mathrm{m}$. (B) The relative fluorescence intensity of STA-2::GFP in the nucleus under the same conditions; $\mathrm{n}=51$ (NI) and 68 (Infec). (C) Ratio of the expression of $n l p$ and $c n c$ gene expression in infected to non-infected worms, measured by quantitative RT-PCR analysis, assayed from the same samples. (D, E) Results for an independent biological replicate for the experiments shown in $(\mathbf{B})$ and $(\mathbf{C})$, respectively; $\mathrm{n}=67(\mathrm{NI})$ and 74 (Infec). ${ }^{* * *} \mathrm{p}<0.001,{ }^{* * *} \mathrm{p}<0.0001$, Mann-Whitney test. (PDF)

S7 Fig. Representative pairs of images (left, white light; right, green fluorescence) of adult atf$4 p(u O R F):: G F P$ reporter worms (LD1499) after $7 \mathrm{~h}$ (bottom left 2 panels) and $24 \mathrm{~h}$ (bottom right 2 panels) of infection with $D$. coniospora, or aged matched non-infected worms (NI, top 4 panels). Scale bar, $200 \mu \mathrm{m}$.

(PDF)

S8 Fig. Quantitative RT-PCR analysis of the expression of $h s p-4, h s p-6, h s p-60$, gst-4 and $g p d h-1$ in worms expressing DcEntA (IG1926), DcEntB (IG1925) or DcEntC (IG1880). Results are presented relative to control worms (JDW141). (PDF)

S9 Fig. HCD fragment mass spectrum of peptide sequence TAGASNWIANK, identifying asparagine N275 as a mono-ADP-ribosylation (MAR) site of DcEntA. The generated fragment ions matched to the theoretical mass spectrum of the peptide are marked as b-ions (the product when the charge is retained on the $\mathrm{N}$-terminus; blue), $\mathrm{y}$-ions (when the charge is retained on the C-terminus; red; spanning the MAR-modified residue) and their corresponding ions with a neutral loss $\left(\mathrm{H}_{2} \mathrm{O}\right.$ or $\mathrm{NH}_{3}$; gold). The positions of fragmentation are shown in the inset peptide sequence. Diagnostic ions (pink) of AMP and ADP were generated by breakage of the MAR group during HCD fragmentation.

(PDF)

S10 Fig. (A) Representative confocal images of hyp7 nuclei in young adult worms expressing FIB-1::GFP with (DcEntB, IG1984; lower two panels) or without (Control; IG1596; upper two panels) DcEntB. (B) Representative confocal images of hyp7 nuclei in young adult worms expressing FIB-1::GFP and DcEntB (IG1984) on sta-1 (upper two panels) or sta-2 (lower two panels) RNAi. Only the green channel is shown. Scale bar, $5 \mu \mathrm{m}$.

$(\mathrm{PDF})$ 
S11 Fig. (A) Representative confocal images of hyp7 nuclei in young adult IG1596 worms expressing FIB-1::GFP after $24 \mathrm{~h}$ infection as young adults at $25^{\circ} \mathrm{C}$ (Infected; lower two panels) or in uninfected animals (Control; upper two panels). (B) Representative confocal images of hyp7 nuclei in young adult IG1596 worms expressing FIB-1::GFP after 6 h CHX exposure (CHX; lower two panels) or without CHX exposure (Control; upper two panels). Only the green channel is shown. Scale bar, $5 \mu \mathrm{m}$.

S1 Table. Full genotypes of transgenic strains. (DOCX)

S2 Table. Oligonucleotide primers. (DOCX)

S3 Table. Phenotypes of transgenic worms expressing one of the 3 candidate virulence factors.

(DOCX)

S4 Table. Identification of protein-protein interactors for DcEntA. The first sheet gives quantitative summary statistics for the significant and specific candidate protein-protein interactors for DcEntA obtained from results for analyses of 3 independent samples, referenced to Wormbase release WS275. The subsequent sheets report annotations and gene enrichments using Wormbase tools and WS277. The GeneIDs of the candidate interactors did not evolve between WS275 and WS277.

(XLSX)

S5 Table. Identification of protein-protein interactors for DcEntB. The first sheet gives quantitative summary statistics for the significant and specific candidate protein-protein interactors for DcEntB obtained from results for analyses of 3 independent samples, referenced to Wormbase release WS275. The subsequent sheets report annotations and gene enrichments using Wormbase tools and WS277. The GeneIDs of the candidate interactors did not evolve between WS275 and WS277.

(XLSX)

\section{Acknowledgments}

We thank Shizue Omi for her contribution, Jerome Belougne for worm sorting, the staff of the CIML imaging core facility, Pierre Golstein for constructive criticism, and Andrew Chisholm for reagents. Some strains were provided by the Caenorhabditis Genetics Center (CGC) that is supported by the National Institutes of Health-Office of Research Infrastructure Programs (P40 OD010440). Others were kind gifts from Collin Ewald, Michel Labouesse, Grégoire Michaux, Xiaochen Wang, Jordan Ward and Benjamin Weaver.

\section{Author Contributions}

Conceptualization: Nathalie Pujol, Jonathan J. Ewbank.

Data curation: Jonathan J. Ewbank.

Formal analysis: Xing Zhang, Benjamin W. Harding, Dina Aggad, Damien Courtine, JiaXuan Chen, Nathalie Pujol, Jonathan J. Ewbank.

Funding acquisition: Jonathan J. Ewbank. 
Investigation: Xing Zhang, Benjamin W. Harding, Dina Aggad, Jia-Xuan Chen, Nathalie Pujol.

Methodology: Benjamin W. Harding, Jia-Xuan Chen, Nathalie Pujol.

Project administration: Jonathan J. Ewbank.

Resources: Xing Zhang.

Software: Damien Courtine.

Supervision: Nathalie Pujol, Jonathan J. Ewbank.

Validation: Xing Zhang, Benjamin W. Harding, Dina Aggad, Jia-Xuan Chen, Jonathan J. Ewbank.

Visualization: Xing Zhang, Dina Aggad, Jia-Xuan Chen, Nathalie Pujol.

Writing - original draft: Xing Zhang, Nathalie Pujol, Jonathan J. Ewbank.

Writing - review \& editing: Xing Zhang, Benjamin W. Harding, Damien Courtine, Nathalie Pujol, Jonathan J. Ewbank.

\section{References}

1. Woolhouse ME, Webster JP, Domingo E, Charlesworth B, Levin BR. Biological and biomedical implications of the co-evolution of pathogens and their hosts. Nat Genet. 2002; 32(4):569-77. Epub 2002/ 11/29. https://doi.org/10.1038/ng1202-569 PMID: 12457190.

2. Lebrigand K, He LD, Thakur N, Arguel MJ, Polanowska J, Henrissat B, et al. Comparative Genomic Analysis of Drechmeria coniospora Reveals Core and Specific Genetic Requirements for Fungal Endoparasitism of Nematodes. PLoS Genet. 2016; 12(5):e1006017. https://doi.org/10.1371/journal. pgen.1006017 PMID: 27153332.

3. He LD, Ewbank JJ. Polyethylene Glycol-mediated Transformation of Drechmeria coniospora. Bio-protocol. 2017; 7(5):9. https://doi.org/10.21769/BioProtoc.2157 PMID: WOS:000457803000011.

4. Darby $\mathrm{C}$, Falkow $\mathrm{S}$. Mimicry of a $\mathrm{G}$ protein mutation by pertussis toxin expression in transgenic Caenorhabditis elegans. Infect Immun. 2001; 69(10):6271-5. Epub 2001/09/13. https://doi.org/10.1128/ IAI.69.10.6271-6275.2001 PMID: 11553570; PubMed Central PMCID: PMC98761.

5. Lee SH, Omi S, Thakur N, Taffoni C, Belougne J, Engelmann I, et al. Modulatory upregulation of an insulin peptide gene by different pathogens in C. elegans. Virulence. 2018; 9(1):648-58. https://doi. org/10.1080/21505594.2018.1433969 PMID: 29405821.

6. Couillault C, Pujol N, Reboul J, Sabatier L, Guichou JF, Kohara Y, et al. TLR-independent control of innate immunity in Caenorhabditis elegans by the TIR domain adaptor protein TIR-1, an ortholog of human SARM. Nat Immunol. 2004; 5:488-94. https://doi.org/10.1038/ni1060 PMID: 15048112.

7. Krueger KM, Barbieri JT. The family of bacterial ADP-ribosylating exotoxins. Clin Microbiol Rev. 1995; 8(1):34-47. Epub 1995/01/01. https://doi.org/10.1128/CMR.8.1.34 PMID: 7704894; PubMed Central PMCID: PMC172848.

8. Wang R, Dong L, He R, Wang Q, Chen Y, Qu L, et al. Comparative genomic analyses reveal the features for adaptation to nematodes in fungi. DNA Res. 2018; 25(3):245-56. Epub 2018/01/10. https:// doi.org/10.1093/dnares/dsx053 PMID: 29315395; PubMed Central PMCID: PMC6014366.

9. Kunzler M. How fungi defend themselves against microbial competitors and animal predators. PLoS Pathog. 2018; 14(9):e1007184. Epub 2018/09/07. https://doi.org/10.1371/journal.ppat.1007184 PMID: 30188951; PubMed Central PMCID: PMC6126850.

10. Stiernagle T, editor. Maintenance of $C$. elegans. http://www.wormbook.org: The C. elegans Research Community ed; 2006. https://doi.org/10.1895/wormbook.1.101.1 PMID: 18050451

11. Courtine D, Provaznik J, Reboul J, Blanc G, Benes V, Ewbank JJ. Long-read only assembly of Drechmeria coniospora genomes reveals widespread chromosome plasticity and illustrates the limitations of current nanopore methods. Gigascience. 2020; 9(9). Epub 2020/09/19. https://doi.org/10.1093/ gigascience/giaa099 PMID: 32947622; PubMed Central PMCID: PMC7500977.

12. Powell JR, Ausubel FM. Models of Caenorhabditis elegans Infection by Bacterial and Fungal Pathogens. In: Ewbank J, Vivier E, editors. Methods Mol Biol. 415: Humana Press; 2008. p. 403-27. https://doi.org/10.1007/978-1-59745-570-1_24 PMID: 18370168 
13. Sinner MP, Masurat F, Ewbank JJ, Pujol N, Bringmann H. Innate Immunity Promotes Sleep through Epidermal Antimicrobial Peptides. Curr Biol. 2021; 31(3):564-77 e12. Epub 2020/12/02. https://doi. org/10.1016/j.cub.2020.10.076 PMID: 33259791.

14. Xu S, Chisholm AD. A Galpha(q)-Ca(2+) signaling pathway promotes actin-mediated epidermal wound closure in C. elegans. Curr Biol. 2011;21:1960-7. Epub 2011/11/22. https://doi.org/10.1016/j. cub.2011.10.050 PMID: 22100061.

15. Gibson DG, Young L, Chuang RY, Venter JC, Hutchison CA 3rd, Smith HO. Enzymatic assembly of DNA molecules up to several hundred kilobases. Nature methods. 2009; 6(5):343-5. Epub 2009/04/ 14. https://doi.org/10.1038/nmeth.1318 PMID: 19363495.

16. Kasimatis KR, Moerdyk-Schauwecker MJ, Phillips PC. Auxin-Mediated Sterility Induction System for Longevity and Mating Studies in Caenorhabditis elegans. G3 (Bethesda). 2018; 8(8):2655-62. https:// doi.org/10.1534/g3.118.200278 PMID: 29880556; PubMed Central PMCID: PMC6071612.

17. Ashley GE, Duong T, Levenson MT, Martinez MAQ, Johnson LC, Hibshman JD, et al. An expanded auxin-inducible degron toolkit for Caenorhabditis elegans. Genetics. 2021; 217(3). Epub 2021/03/08. https://doi.org/10.1093/genetics/iyab006 PMID: 33677541.

18. Pujol N, Cypowyj S, Ziegler K, Millet A, Astrain A, Goncharov A, et al. Distinct innate immune responses to infection and wounding in the $C$. elegans epidermis. Curr Biol. 2008; 18(7):481-9. Epub 2008/04/09. https://doi.org/10.1016/j.cub.2008.02.079 PMID: 18394898.

19. Pujol N, Zugasti O, Wong D, Couillault C, Kurz CL, Schulenburg H, et al. Anti-fungal innate immunity in C. elegans is enhanced by evolutionary diversification of antimicrobial peptides. PLoS Pathog. 2008; 4 (7):e1000105. Epub 2008/07/19. https://doi.org/10.1371/journal.ppat.1000105 PMID: 18636113.

20. Schindelin J, Arganda-Carreras I, Frise E, Kaynig V, Longair M, Pietzsch T, et al. Fiji: an open-source platform for biological-image analysis. Nat Methods. 2012; 9(7):676-82. Epub 2012/06/30. https://doi. org/10.1038/nmeth.2019 PMID: 22743772; PubMed Central PMCID: PMC3855844.

21. Kamath RS, Ahringer J. Genome-wide RNAi screening in Caenorhabditis elegans. Methods. 2003; 30 (4):313-21. https://doi.org/10.1016/s1046-2023(03)00050-1 PMID: 12828945.

22. Rual JF, Ceron J, Koreth J, Hao T, Nicot AS, Hirozane-Kishikawa T, et al. Toward improving Caenorhabditis elegans phenome mapping with an ORFeome-based RNAi library. Genome Res. 2004; 14 (10B):2162-8. https://doi.org/10.1101/gr.2505604 PMID: 15489339.

23. Tong A, Lynn G, Ngo V, Wong D, Moseley SL, Ewbank JJ, et al. Negative regulation of Caenorhabditis elegans epidermal damage responses by death-associated protein kinase. Proc Natl Acad Sci U S A. 2009; 106(5):1457-61. https://doi.org/10.1073/pnas.0809339106 PMID: 19164535.

24. Eberhard R, Stergiou L, Hofmann ER, Hofmann J, Haenni S, Teo Y, et al. Ribosome synthesis and MAPK activity modulate ionizing radiation-induced germ cell apoptosis in Caenorhabditis elegans. PLoS Genet. 2013; 9(11):e1003943. Epub 2013/11/28. https://doi.org/10.1371/journal.pgen.1003943 PMID: 24278030; PubMed Central PMCID: PMC3836707.

25. Rappsilber J, Ishihama $Y$, Mann M. Stop and go extraction tips for matrix-assisted laser desorption/ ionization, nanoelectrospray, and LC/MS sample pretreatment in proteomics. Anal Chem. 2003; 75 (3):663-70. https://doi.org/10.1021/ac026117i PMID: 12585499.

26. Cox J, Mann M. MaxQuant enables high peptide identification rates, individualized p.p.b.-range mass accuracies and proteome-wide protein quantification. Nat Biotechnol. 2008; 26(12):1367-72. https:// doi.org/10.1038/nbt.1511 PMID: 19029910.

27. Cox J, Neuhauser N, Michalski A, Scheltema RA, Olsen JV, Mann M. Andromeda: a peptide search engine integrated into the MaxQuant environment. J Proteome Res. 2011; 10(4):1794-805. https:// doi.org/10.1021/pr101065j PMID: 21254760.

28. Martello R, Leutert M, Jungmichel S, Bilan V, Larsen SC, Young C, et al. Proteome-wide identification of the endogenous ADP-ribosylome of mammalian cells and tissue. Nat Commun. 2016; 7:12917. Epub 2016/10/01. https://doi.org/10.1038/ncomms12917 PMID: 27686526; PubMed Central PMCID: PMC5056437.

29. Cox J, Hein MY, Luber CA, Paron I, Nagaraj N, Mann M. Accurate proteome-wide label-free quantification by delayed normalization and maximal peptide ratio extraction, termed MaxLFQ. Mol Cell Proteomics. 2014; 13(9):2513-26. https://doi.org/10.1074/mcp.M113.031591 PMID: 24942700; PubMed Central PMCID: PMC4159666.

30. Perez-Riverol Y, Csordas A, Bai J, Bernal-Llinares M, Hewapathirana S, Kundu DJ, et al. The PRIDE database and related tools and resources in 2019: improving support for quantification data. Nucleic Acids Res. 2019; 47(D1):D442-D50. Epub 2018/11/06. https://doi.org/10.1093/nar/gky1106 PMID: 30395289; PubMed Central PMCID: PMC6323896.

31. Tusher VG, Tibshirani R, Chu G. Significance analysis of microarrays applied to the ionizing radiation response. Proc Natl Acad Sci U S A. 2001; 98(9):5116-21. https://doi.org/10.1073/pnas.091062498 PMID: 11309499; PubMed Central PMCID: PMC33173. 
32. Li W. Volcano plots in analyzing differential expressions with mRNA microarrays. J Bioinform Comput Biol. 2012; 10(6):1231003. https://doi.org/10.1142/S0219720012310038 PMID: 23075208.

33. Scott MS, Troshin PV, Barton GJ. NoD: a Nucleolar localization sequence detector for eukaryotic and viral proteins. BMC Bioinformatics. 2011; 12:317. Epub 2011/08/05. https://doi.org/10.1186/14712105-12-317 PMID: 21812952; PubMed Central PMCID: PMC3166288.

34. Cox GN, Hirsh D. Stage-specific patterns of collagen gene expression during development of Caenorhabditis elegans. Mol Cell Biol. 1985; 5(2):363-72. Epub 1985/02/01. https://doi.org/10.1128/mcb.5.2. 363-372.1985 PMID: 2983191; PubMed Central PMCID: PMC366719.

35. Liu Z, Kirch S, Ambros V. The Caenorhabditis elegans heterochronic gene pathway controls stagespecific transcription of collagen genes. Development. 1995; 121(8):2471-8. Epub 1995/08/01. PMID: 7671811.

36. Zhang L, Ward JD, Cheng Z, Dernburg AF. The auxin-inducible degradation (AID) system enables versatile conditional protein depletion in C. elegans. Development. 2015; 142(24):4374-84. https:// doi.org/10.1242/dev.129635 PMID: 26552885; PubMed Central PMCID: PMC4689222.

37. Yi YH, Ma TH, Lee LW, Chiou PT, Chen PH, Lee CM, et al. A Genetic Cascade of let-7-ncl-1-fib-1 Modulates Nucleolar Size and rRNA Pool in Caenorhabditis elegans. PLoS Genet. 2015; 11(10): e1005580. Epub 2015/10/23. https://doi.org/10.1371/journal.pgen.1005580 PMID: 26492166; PubMed Central PMCID: PMC4619655.

38. Bhoi A, Palladino F, Fabrizio P. Auxin confers protection against ER stress in Caenorhabditis elegans. bioRxiv. 2020:2020.11.15.383760. https://doi.org/10.1101/2020.11.15.383760

39. Pujol N, Davis PA, Ewbank JJ. The Origin and Function of Anti-Fungal Peptides in C. elegans: Open Questions. Front Immunol. 2012; 3:237. Epub 2012/08/08. https://doi.org/10.3389/fimmu.2012.00237 PMID: 22870075; PubMed Central PMCID: PMC3409374.

40. Zugasti O, Ewbank JJ. Neuroimmune regulation of antimicrobial peptide expression by a noncanonical TGF-beta signaling pathway in Caenorhabditis elegans epidermis. Nat Immunol. 2009; 10(3):249-56. https://doi.org/10.1038/ni.1700 PMID: 19198592.

41. Kim KW, Thakur N, Piggott CA, Omi S, Polanowska J, Jin Y, et al. Coordinated inhibition of C/EBP by Tribbles in multiple tissues is essential for Caenorhabditis elegans development. BMC Biol. 2016; 14 (1):104. https://doi.org/10.1186/s12915-016-0320-z PMID: 27927209; PubMed Central PMCID: PMC5141650.

42. Polanowska J, Chen JX, Soule J, Omi S, Belougne J, Taffoni C, et al. Evolutionary plasticity in the innate immune function of Akirin. PLoS Genet. 2018; 14(7):e1007494. https://doi.org/10.1371/journal. pgen.1007494 PMID: 30036395; PubMed Central PMCID: PMC6072134.

43. Zugasti O, Thakur N, Belougne J, Squiban B, Kurz CL, Soule J, et al. A quantitative genome-wide RNAi screen in C. elegans for antifungal innate immunity genes. BMC Biol. 2016; 14(1):35. https://doi. org/10.1186/s12915-016-0256-3 PMID: 27129311; PubMed Central PMCID: PMC4850687.

44. Zugasti O, Bose N, Squiban B, Belougne J, Kurz CL, Schroeder FC, et al. Activation of a G proteincoupled receptor by its endogenous ligand triggers the innate immune response of Caenorhabditis elegans. Nat Immunol. 2014; 15(9):833-8. Epub 2014/08/05. https://doi.org/10.1038/ni.2957 PMID: 25086774; PubMed Central PMCID: PMC4139443.

45. Ziegler K, Kurz CL, Cypowyj S, Couillault C, Pophillat M, Pujol N, et al. Antifungal innate immunity in $C$. elegans: PKCdelta links G protein signaling and a conserved p38 MAPK cascade. Cell Host Microbe. 2009; 5(4):341-52. Epub 2009/04/22. https://doi.org/10.1016/j.chom.2009.03.006 PMID: 19380113.

46. Labed SA, Omi S, Gut M, Ewbank JJ, Pujol N. The pseudokinase NIPI-4 is a novel regulator of antimicrobial peptide gene expression. PLoS One. 2012; 7(3):e33887. Epub 2012/04/04. https://doi.org/10. 1371/journal.pone.0033887 PMID: 22470487; PubMed Central PMCID: PMC3309975.

47. Weaver BP, Weaver YM, Omi S, Yuan W, Ewbank JJ, Han M. Non-Canonical Caspase Activity Antagonizes p38 MAPK Stress-Priming Function to Support Development. Dev Cell. 2020; 53(3):358-69. e6. https://doi.org/10.1016/j.devcel.2020.03.015 PMID: 32302544

48. Dierking K, Polanowska J, Omi S, Engelmann I, Gut M, Lembo F, et al. Unusual regulation of a STAT protein by an SLC6 family transporter in $C$. elegans epidermal innate immunity. Cell Host Microbe. 2011; 9(5):425-35. Epub 2011/05/18. https://doi.org/10.1016/j.chom.2011.04.011 PMID: 21575913.

49. Taffoni C, Omi S, Huber C, Mailfert S, Fallet M, Rupprecht JF, et al. Microtubule plus-end dynamics link wound repair to the innate immune response. Elife. 2020; 9:e45047. Epub 2020/01/30. https://doi. org/10.7554/eLife.45047 PMID: 31995031; PubMed Central PMCID: PMC PMC7043892.

50. Engelmann I, Griffon A, Tichit L, Montanana-Sanchis F, Wang G, Reinke V, et al. A comprehensive analysis of gene expression changes provoked by bacterial and fungal infection in $C$. elegans. PLoS One. 2011; 6(5):e19055. Epub 2011/05/24. https://doi.org/10.1371/journal.pone.0019055 PMID: 21602919; PubMed Central PMCID: PMC3094335. 
51. Omi S, Zhang $X$, Thakur N, Pujol N. ifas-1 is upregulated by fungal infection in a GPA-12 and STA-2independent manner in the Caenorhabditis elegans epidermis. MicroPubl Biol. 2021; 2021. Epub 2021/06/01. https://doi.org/10.17912/micropub.biology.000400 PMID: 34056565; PubMed Central PMCID: PMC8150249.

52. Watts JS, Harrison HF, Omi S, Guenthers Q, Dalelio J, Pujol N, et al. New Strains for Tissue-Specific RNAi Studies in Caenorhabditis elegans. G3 (Bethesda). 2020; 10(11):4167-76. Epub 2020/09/19. https://doi.org/10.1534/g3.120.401749 PMID: 32943454; PubMed Central PMCID: PMC7642939.

53. Mandal M, Powers SE, Maienschein-Cline M, Bartom ET, Hamel KM, Kee BL, et al. Epigenetic repression of the lgk locus by STAT5-mediated recruitment of the histone methyltransferase Ezh2. Nat Immunol. 2011; 12(12):1212-20. Epub 2011/11/01. https://doi.org/10.1038/ni.2136 PMID: 22037603; PubMed Central PMCID: PMC3233979.

54. Tanguy M, Veron L, Stempor $P$, Ahringer J, Sarkies $P$, Miska EA. An Alternative STAT Signaling Pathway Acts in Viral Immunity in Caenorhabditis elegans. MBio. 2017; 8(5). https://doi.org/10.1128/mBio. 00924-17 PMID: 28874466; PubMed Central PMCID: PMC5587905.

55. Reddy KC, Dror T, Sowa JN, Panek J, Chen K, Lim ES, et al. An Intracellular Pathogen Response Pathway Promotes Proteostasis in C. elegans. Curr Biol. 2017; 27(22):3544-53. https://doi.org/10. 1016/j.cub.2017.10.009 PMID: 29103937; PubMed Central PMCID: PMC5698132.

56. Reddy KC, Dror T, Underwood RS, Osman GA, Elder CR, Desjardins CA, et al. Antagonistic paralogs control a switch between growth and pathogen resistance in C. elegans. PLoS Pathog. 2019; 15(1): e1007528. https://doi.org/10.1371/journal.ppat.1007528 PubMed Central PMCID: PMC6347328. PMID: 30640956

57. Dunbar TL, Yan Z, Balla KM, Smelkinson MG, Troemel ER. C. elegans detects pathogen-induced translational inhibition to activate immune signaling. Cell Host Microbe. 2012; 11(4):375-86. Epub 2012/04/24. https://doi.org/10.1016/j.chom.2012.02.008 S1931-3128(12)00092-3 [pii]. PMID: 22520465; PubMed Central PMCID: PMC3334869.

58. McEwan DL, Kirienko NV, Ausubel FM. Host translational inhibition by Pseudomonas aeruginosa Exotoxin A Triggers an immune response in Caenorhabditis elegans. Cell Host Microbe. 2012; 11(4):36474. Epub 2012/04/24. https://doi.org/10.1016/j.chom.2012.02.007 S1931-3128(12)00091-1 [pii]. PMID: 22520464; PubMed Central PMCID: PMC3334877.

59. Estes KA, Dunbar TL, Powell JR, Ausubel FM, Troemel ER. bZIP transcription factor zip-2 mediates an early response to Pseudomonas aeruginosa infection in Caenorhabditis elegans. Proc Natl Acad Sci U S A. 2010; 107(5):2153-8. https://doi.org/10.1073/pnas.0914643107 PMID: 20133860.

60. Kudron MM, Victorsen A, Gevirtzman L, Hillier LW, Fisher WW, Vafeados D, et al. The ModERN Resource: Genome-Wide Binding Profiles for Hundreds of Drosophila and Caenorhabditis elegans Transcription Factors. Genetics. 2018; 208(3):937-49. Epub 2017/12/30. https://doi.org/10.1534/ genetics.117.300657 PMID: 29284660; PubMed Central PMCID: PMC5844342.

61. Rousakis A, Vlassis A, Vlanti A, Patera S, Thireos G, Syntichaki P. The general control nonderepressible-2 kinase mediates stress response and longevity induced by target of rapamycin inactivation in Caenorhabditis elegans. Aging Cell. 2013; 12(5):742-51. Epub 2013/05/23. https://doi.org/10.1111/ acel.12101 PMID: 23692540; PubMed Central PMCID: PMC4225475.

62. Statzer C, Venz R, Bland M, Robida-Stubbs S, Meng J, Patel K, et al. ATF-4 and hydrogen sulfide signalling mediate longevity from inhibition of translation or mTORC1. bioRxiv. 2020: 2020.11.02.364703. https://doi.org/10.1101/2020.11.02.364703

63. Venz R, Korosteleva A, Jongsma E, Ewald CY. Combining Auxin-Induced Degradation and RNAi Screening Identifies Novel Genes Involved in Lipid Bilayer Stress Sensing in Caenorhabditis elegans. G3 (Bethesda). 2020; 10(11):3921-8. Epub 2020/09/23. https://doi.org/10.1534/g3.120.401635 PMID: 32958476; PubMed Central PMCID: PMC7642917.

64. Hoppe T, Cohen E. Organismal Protein Homeostasis Mechanisms. Genetics. 2020; 215(4):889-901. Epub 2020/08/08. https://doi.org/10.1534/genetics.120.301283 PMID: 32759342; PubMed Central PMCID: PMC7404231.

65. Couillault C, Fourquet P, Pophillat M, Ewbank JJ. A UPR-independent infection-specific role for a BiP/ GRP78 protein in the control of antimicrobial peptide expression in C. elegans epidermis. Virulence. 2012; 3(3):299-308. Epub 2012/05/02. https://doi.org/10.4161/viru.20384 PubMed Central PMCID: PMC3442842. PMID: 22546897

66. Jones D, Dixon DK, Graham RW, Candido EP. Differential regulation of closely related members of the hsp16 gene family in Caenorhabditis elegans. DNA. 1989; 8(7):481-90. Epub 1989/09/01. https:// doi.org/10.1089/dna.1.1989.8.481 PMID: 2475316.

67. Calfon M, Zeng H, Urano F, Till JH, Hubbard SR, Harding HP, et al. IRE1 couples endoplasmic reticulum load to secretory capacity by processing the XBP-1 mRNA. Nature. 2002; 415(6867):92-6. https://doi.org/10.1038/415092a PMID: 11780124. 
68. Yoneda T, Benedetti C, Urano F, Clark SG, Harding HP, Ron D. Compartment-specific perturbation of protein handling activates genes encoding mitochondrial chaperones. J Cell Sci. 2004; 117(Pt 18):4055-66. https://doi.org/10.1242/jcs.01275 PMID: 15280428.

69. Link CD, Johnson CJ. Reporter transgenes for study of oxidant stress in Caenorhabditis elegans. Methods Enzymol. 2002; 353:497-505. Epub 2002/06/25. https://doi.org/10.1016/s0076-6879(02) 53072-x PMID: 12078522.

70. Lamitina T, Huang CG, Strange K. Genome-wide RNAi screening identifies protein damage as a regulator of osmoprotective gene expression. Proc Natl Acad Sci U S A. 2006; 103(32):12173-8. https:// doi.org/10.1073/pnas.0602987103 PMID: 16880390.

71. Moss J, Vaughan M. Structure and function of ARF proteins: activators of cholera toxin and critical components of intracellular vesicular transport processes. J Biol Chem. 1995; 270(21):12327-30. Epub 1995/05/26. https://doi.org/10.1074/jbc.270.21.12327 PMID: 7759471.

72. Kahn RA, Gilman AG. The protein cofactor necessary for ADP-ribosylation of Gs by cholera toxin is itself a GTP binding protein. J Biol Chem. 1986; 261(17):7906-11. Epub 1986/06/15. PMID: 3086320.

73. Angeles-Albores D, Lee R, Chan J, Sternberg P. Two new functions in the WormBase Enrichment Suite. MicroPubl Biol. 2018; 2018. Epub 2018/03/27. https://doi.org/10.17912/W25Q2N PMID: 32550381 ; PubMed Central PMCID: PMC7255849.

74. Gengyo-Ando K, Kuroyanagi H, Kobayashi T, Murate M, Fujimoto K, Okabe S, et al. The SM protein VPS-45 is required for RAB-5-dependent endocytic transport in Caenorhabditis elegans. EMBO Rep. 2007; 8(2):152-7. Epub 2007/01/20. https://doi.org/10.1038/sj.embor.7400882 PMID: 17235359; PubMed Central PMCID: PMC1796764.

75. Waaijers S, Munoz J, Berends C, Ramalho JJ, Goerdayal SS, Low TY, et al. A tissue-specific protein purification approach in Caenorhabditis elegans identifies novel interaction partners of DLG-1/Discs large. BMC Biol. 2016; 14:66. Epub 2016/08/11. https://doi.org/10.1186/s12915-016-0286-x PMID: 27506200; PubMed Central PMCID: PMC4977824.

76. Liu H, Wang S, Hang W, Gao J, Zhang W, Cheng Z, et al. LET-413/Erbin acts as a RAB-5 effector to promote RAB-10 activation during endocytic recycling. J Cell Biol. 2018; 217(1):299-314. Epub 2017/ 10/29. https://doi.org/10.1083/jcb.201705136 PMID: 29079669; PubMed Central PMCID: PMC5748983.

77. Bidaud-Meynard A, Nicolle O, Heck M, Le Cunff Y, Michaux G. A V0-ATPase-dependent apical trafficking pathway maintains the polarity of the intestinal absorptive membrane. Development. 2019; 146 (11). Epub 2019/05/22. https://doi.org/10.1242/dev.174508 PMID: 31110027; PubMed Central PMCID: PMC7376742.

78. Latonen L. Phase-to-Phase With Nucleoli-Stress Responses, Protein Aggregation and Novel Roles of RNA. Front Cell Neurosci. 2019; 13:151. Epub 2019/05/14. https://doi.org/10.3389/fncel.2019. 00151 PMID: 31080406; PubMed Central PMCID: PMC6497782.

79. Tiku V, Kew C, Mehrotra P, Ganesan R, Robinson N, Antebi A. Nucleolar fibrillarin is an evolutionarily conserved regulator of bacterial pathogen resistance. Nat Commun. 2018; 9(1):3607. https://doi.org/ 10.1038/s41467-018-06051-1 PMID: 30190478; PubMed Central PMCID: PMC6127302.

80. Fuhrman LE, Goel AK, Smith J, Shianna KV, Aballay A. Nucleolar proteins suppress Caenorhabditis elegans innate immunity by inhibiting p53/CEP-1. PLoS Genet. 2009; 5(9):e1000657. Epub 2009/09/ 19. https://doi.org/10.1371/journal.pgen.1000657 PMID: 19763173; PubMed Central PMCID: PMC2734340.

81. Caragine CM, Haley SC, Zidovska A. Nucleolar dynamics and interactions with nucleoplasm in living cells. Elife. 2019; 8:e47533. Epub 2019/11/27. https://doi.org/10.7554/eLife.47533 PMID: 31769409; PubMed Central PMCID: PMC6879204.

82. Du X, Rao MR, Chen XQ, Wu W, Mahalingam S, Balasundaram D. The homologous putative GTPases Grn1p from fission yeast and the human GNL3L are required for growth and play a role in processing of nucleolar pre-rRNA. Mol Biol Cell. 2006; 17(1):460-74. Epub 2005/10/28. https://doi. org/10.1091/mbc.e05-09-0848 PMID: 16251348; PubMed Central PMCID: PMC1345682.

83. Eliyahu E, Tirosh O, Dobesova M, Nachshon A, Schwartz M, Stern-Ginossar N. Rho-Associated Coiled-Coil Kinase 1 Translocates to the Nucleus and Inhibits Human Cytomegalovirus Propagation. J Virol. 2019; 93(19):e00453-19. Epub 2019/07/12. https://doi.org/10.1128/JVI.00453-19 PMID: 31292242; PubMed Central PMCID: PMC6744247.

84. Green RA, Kao HL, Audhya A, Arur S, Mayers JR, Fridolfsson HN, et al. A high-resolution C. elegans essential gene network based on phenotypic profiling of a complex tissue. Cell. 2011; 145(3):470-82. Epub 2011/05/03. https://doi.org/10.1016/j.cell.2011.03.037 PMID: 21529718; PubMed Central PMCID: PMC3086541. 
85. Bonfiglio JJ, Colby T, Matic I. Mass spectrometry for serine ADP-ribosylation? Think o-glycosylation! Nucleic Acids Res. 2017; 45(11):6259-64. Epub 2017/05/19. https://doi.org/10.1093/nar/gkx446 PMID: 28520971; PubMed Central PMCID: PMC5499872.

86. Weill U, Krieger G, Avihou Z, Milo R, Schuldiner M, Davidi D. Assessment of GFP Tag Position on Protein Localization and Growth Fitness in Yeast. J Mol Biol. 2019; 431(3):636-41. Epub 2018/12/15. https://doi.org/10.1016/j.jmb.2018.12.004 PMID: 30550779.

87. Bischof J, Bjorklund M, Furger E, Schertel C, Taipale J, Basler K. A versatile platform for creating a comprehensive UAS-ORFeome library in Drosophila. Development. 2013; 140(11):2434-42. Epub 2013/05/03. https://doi.org/10.1242/dev.088757 PMID: 23637332.

88. Huh WK, Falvo JV, Gerke LC, Carroll AS, Howson RW, Weissman JS, et al. Global analysis of protein localization in budding yeast. Nature. 2003; 425(6959):686-91. Epub 2003/10/17. https://doi.org/10. 1038/nature02026 PMID: 14562095.

89. Robin GP, Kleemann J, Neumann U, Cabre L, Dallery JF, Lapalu N, et al. Subcellular Localization Screening of Colletotrichum higginsianum Effector Candidates Identifies Fungal Proteins Targeted to Plant Peroxisomes, Golgi Bodies, and Microtubules. Front Plant Sci. 2018; 9:562. Epub 2018/05/18. https://doi.org/10.3389/fpls.2018.00562 PMID: 29770142; PubMed Central PMCID: PMC5942036.

90. Youssar L, Wernet V, Hensel N, Yu X, Hildebrand HG, Schreckenberger B, et al. Intercellular communication is required for trap formation in the nematode-trapping fungus Duddingtonia flagrans. PLoS Genet. 2019; 15(3):e1008029. https://doi.org/10.1371/journal.pgen.1008029 PMID: 30917129; PubMed Central PMCID: PMC6453484.

91. Lo Presti L, Lanver D, Schweizer G, Tanaka S, Liang L, Tollot M, et al. Fungal effectors and plant susceptibility. Annu Rev Plant Biol. 2015; 66:513-45. https://doi.org/10.1146/annurev-arplant-043014114623 PMID: 25923844.

92. Reddick LE, Alto NM. Bacteria fighting back: how pathogens target and subvert the host innate immune system. Mol Cell. 2014; 54(2):321-8. Epub 2014/04/29. https://doi.org/10.1016/j.molcel. 2014.03.010 PMID: 24766896; PubMed Central PMCID: PMC4023866.

93. Thakur A, Mikkelsen H, Jungersen G. Intracellular Pathogens: Host Immunity and Microbial Persistence Strategies. J Immunol Res. 2019; 2019:1356540. Epub 2019/05/22. https://doi.org/10.1155/ 2019/1356540 PMID: 31111075; PubMed Central PMCID: PMC6487120.

94. Holmes A, Muhlen S, Roe AJ, Dean P. The EspF effector, a bacterial pathogen's Swiss army knife. Infect Immun. 2010; 78(11):4445-53. Epub 2010/08/04. https://doi.org/10.1128/IAI.00635-10 PMID: 20679436; PubMed Central PMCID: PMC2976335.

95. Olson MO. Sensing cellular stress: another new function for the nucleolus? Sci STKE. 2004; 2004 (224):pe10. Epub 2004/03/18. https://doi.org/10.1126/stke.2242004pe10 PMID: 15026578.

96. Rubbi CP, Milner J. Disruption of the nucleolus mediates stabilization of p53 in response to DNA damage and other stresses. Embo J. 2003; 22(22):6068-77. Epub 2003/11/12. https://doi.org/10.1093/ emboj/cdg579 PMID: 14609953; PubMed Central PMCID: PMC275437.

97. Klibanov SA O'Hagan HM, Ljungman M. Accumulation of soluble and nucleolar-associated p53 proteins following cellular stress. J Cell Sci. 2001; 114(Pt 10):1867-73. Epub 2001/05/01. PMID: 11329373.

98. Dean P, Scott JA, Knox AA, Quitard S, Watkins NJ, Kenny B. The enteropathogenic E. coli effector EspF targets and disrupts the nucleolus by a process regulated by mitochondrial dysfunction. PLoS Pathog. 2010; 6(6):e1000961. https://doi.org/10.1371/journal.ppat.1000961 PMID: 20585567; PubMed Central PMCID: PMC2891835.

99. Pukkila-Worley R. Surveillance Immunity: An Emerging Paradigm of Innate Defense Activation in Caenorhabditis elegans. PLoS Pathog. 2016; 12(9):e1005795. https://doi.org/10.1371/journal.ppat. 1005795 PMID: 27631629; PubMed Central PMCID: PMC5025020.

100. Chou TC, Chiu HC, Kuo CJ, Wu CM, Syu WJ, Chiu WT, et al. Enterohaemorrhagic Escherichia coli O157:H7 Shiga-like toxin 1 is required for full pathogenicity and activation of the p38 mitogen-activated protein kinase pathway in Caenorhabditis elegans. Cellular microbiology. 2013; 15(1):82-97. Epub 2012/09/19. https://doi.org/10.1111/cmi.12030 PMID: 22985085.

101. Kim DH, Ewbank JJ. Signaling in the innate immune response: The $C$. elegans Research Community ed.; 2018 PMC6369418]. Available from: https://www.ncbi.nlm.nih.gov/pubmed/26694508.

102. McEwan DL, Feinbaum RL, Stroustrup N, Haas W, Conery AL, Anselmo A, et al. Tribbles ortholog NIPI-3 and bZIP transcription factor CEBP-1 regulate a Caenorhabditis elegans intestinal immune surveillance pathway. BMC Biol. 2016; 14(1):105. https://doi.org/10.1186/s12915-016-0334-6 PMID: $27927200 ;$ PubMed Central PMCID: PMC5143455.

103. Meerupati T, Andersson KM, Friman E, Kumar D, Tunlid A, Ahren D. Genomic mechanisms accounting for the adaptation to parasitism in nematode-trapping fungi. PLoS Genet. 2013; 9(11):e1003909. 
Epub 2013/11/19. https://doi.org/10.1371/journal.pgen.1003909 PMID: 24244185; PubMed Central PMCID: PMC3828140.

104. Liu K, Zhang W, Lai Y, Xiang M, Wang X, Zhang X, et al. Drechslerella stenobrocha genome illustrates the mechanism of constricting rings and the origin of nematode predation in fungi. Bmc Genomics. 2014; 15:114. Epub 2014/02/11. https://doi.org/10.1186/1471-2164-15-114 PMID: 24507587; PubMed Central PMCID: PMC3924618.

105. Larriba E, Jaime MD, Carbonell-Caballero J, Conesa A, Dopazo J, Nislow C, et al. Sequencing and functional analysis of the genome of a nematode egg-parasitic fungus, Pochonia chlamydosporia. Fungal Genet Biol. 2014; 65:69-80. Epub 2014/02/18. https://doi.org/10.1016/j.fgb.2014.02.002 PMID: 24530791.

106. de Bekker C, Ohm RA, Evans HC, Brachmann A, Hughes DP. Ant-infecting Ophiocordyceps genomes reveal a high diversity of potential behavioral manipulation genes and a possible major role for enterotoxins. Sci Rep. 2017; 7(1):12508. Epub 2017/10/04. https://doi.org/10.1038/s41598-017-12863-w PMID: 28970504; PubMed Central PMCID: PMC5624889.

107. Kobmoo N, Wichadakul D, Arnamnart N, Rodriguez De La Vega RC, Luangsa-Ard JJ, Giraud T. A genome scan of diversifying selection in Ophiocordyceps zombie-ant fungi suggests a role for enterotoxins in co-evolution and host specificity. Mol Ecol. 2018; 27(18):3582-98. Epub 2018/07/28. https:// doi.org/10.1111/mec.14813 PMID: 30052297.

108. Krzywinski M, Schein J, Birol I, Connors J, Gascoyne R, Horsman D, et al. Circos: an information aesthetic for comparative genomics. Genome Res. 2009; 19(9):1639-45. Epub 2009/06/23. https://doi. org/10.1101/gr.092759.109 PMID: 19541911; PubMed Central PMCID: PMC2752132.

109. Zhang L, Zhou Z, Guo Q, Fokkens L, Miskei M, Pocsi I, et al. Insights into Adaptations to a Near-Obligate Nematode Endoparasitic Lifestyle from the Finished Genome of Drechmeria coniospora. Sci Rep. 2016; 6:23122. https://doi.org/10.1038/srep23122 PMID: 26975455; PubMed Central PMCID: PMC4792172. 